\title{
Alternating Electric Fields (TTFields) Activate Ca 1.2 Channels in Human Glioblastoma Cells
}

\author{
Eric Neuhaus ${ }^{1,+}$, Lisa Zirjacks ${ }^{1,+}$, Katrin Ganser ${ }^{1}$, Lukas Klumpp ${ }^{1}$, Uwe Schüler ${ }^{2}$, \\ Daniel Zips 1,3 , Franziska Eckert ${ }^{1,3}$ and Stephan M. Huber ${ }^{1, *}$ \\ 1 Department of Radiation Oncology, University of Tübingen, Hoppe-Seyler-Str. 3, 72076 Tübingen, Germany; \\ eric.neuhaus@med.uni-tuebingen.de (E.N.); lisa-zirjacks@web.de (L.Z.); \\ katrin.ganser@med.uni-tuebingen.de (K.G.); lukas.klumpp@med.uni-tuebingen.de (L.K.); \\ daniel.zips@med.uni-tuebingen.de (D.Z.); franziska.eckert@med.uni-tuebingen.de (F.E.) \\ 2 Institute of Applied Physics, University of Tübingen, Auf der Morgenstelle 10, 72076 Tübingen, Germany; \\ uwe.schueler@uni-tuebingen.de \\ 3 German Cancer Consortium (DKTK) partnersite Tübingen, German Cancer Research Center (DKFZ), \\ Im Neuenheimer Feld 280, 69120 Heidelberg, Germany \\ * Correspondence: stephan.huber@uni-tuebingen.de; Tel.: +49-(0)-7071-29-82183 \\ + E.N. and L.Z. contributed equally to this work and, thus, share first-authorship.
}

Received: 25 October 2018; Accepted: 15 January 2019; Published: 18 January 2019

check for updates

\begin{abstract}
Tumor treating fields (TTFields) represent a novel FDA-approved treatment modality for patients with newly diagnosed or recurrent glioblastoma multiforme. This therapy applies intermediate frequency alternating electric fields with low intensity to the tumor volume by the use of non-invasive transducer electrode arrays. Mechanistically, TTFields have been proposed to impair formation of the mitotic spindle apparatus and cytokinesis. In order to identify further potential molecular targets, here the effects of TTFields on $\mathrm{Ca}^{2+}$-signaling, ion channel activity in the plasma membrane, cell cycle, cell death, and clonogenic survival were tested in two human glioblastoma cell lines in vitro by fura- $2 \mathrm{Ca}^{2+}$ imaging, patch-clamp cell-attached recordings, flow cytometry and pre-plated colony formation assay. In addition, the expression of voltage-gated $\mathrm{Ca}^{2+}$ $\left(\mathrm{Ca}_{\mathrm{v}}\right)$ channels was determined by real-time RT-PCR and their significance for the cellular TTFields response defined by knock-down and pharmacological blockade. As a result, TTFields stimulated in a cell line-dependent manner a $\mathrm{Ca}_{\mathrm{v}} 1$.2-mediated $\mathrm{Ca}^{2+}$ entry, $\mathrm{G}_{1}$ or $\mathrm{S}$ phase cell cycle arrest, breakdown of the inner mitochondrial membrane potential and DNA degradation, and/or decline of clonogenic survival suggesting a tumoricidal action of TTFields. Moreover, inhibition of $\mathrm{Ca}_{\mathrm{v}} 1.2$ by benidipine aggravated in one glioblastoma line the TTFields effects suggesting that $\mathrm{Ca}_{\mathrm{v}}$ 1.2-triggered signaling contributes to cellular TTFields stress response. In conclusion, the present study identified $\mathrm{Ca}_{\mathrm{v}} 1.2$ channels as TTFields target in the plasma membrane and provides the rationale to combine TTFields therapy with $\mathrm{Ca}^{2+}$ antagonists that are already in clinical use.
\end{abstract}

Keywords: glioma; alternating electric field therapy; $\mathrm{Ca}^{2+}$ signaling; programmed cell death; clonogenicity; L-type $\mathrm{Ca}^{2+}$ channel; benidipine

\section{Introduction}

Tumor Treating Fields (TTFields) therapy, developed by the company NovoCure (Haifa, Israel) is a new modality of anti-cancer therapy which has been FDA-approved for newly diagnosed and recurrent glioblastoma multiforme and is currently evaluated for several other tumor entities. TTFields apply alternating intermediate-frequency $(200 \mathrm{kHz})$ sine wave-electric fields with low field strength $(1-3 \mathrm{~V} / \mathrm{cm})$ to the tumor with the help of non-invasive ceramic transducer electrode arrays (for glioblastoma patients mounted on the shaved scalp). TTFields were usually administered 20-24 h/day 
for several months [1] concomitantly to temozolomide maintenance therapy after surgical resection of the glioblastoma and subsequent radiochemotherapy with temozolomide. A phase III clinical trial on recurrent glioblastoma comparing TTFields monotherapy with physician's choice chemotherapy indicates that the efficacy of TTFields is similar to chemotherapy with improved toxicity profile [1]. The 6-year-follow-up of a prospective randomized multicenter phase III trial on newly diagnosed glioblastoma comparing standard temozolomide maintenance therapy with standard therapy plus TTFields electrotherapy indicates a significant improvement of progression-free and overall survival by TTFields [2]. Importantly, the adverse side effects of TTFields therapy are restricted to mild to moderate skin rash beneath the transducer arrays [1,3]. Combined these clinical data indicate that TTFields electrotherapy is an effective and safe treatment modality for glioblastoma patients increasingly offered to patients in good performance status willing to wear the electrode arrays.

TTFields reportedly target mitosis and cytokinesis [4-7]. Mechanistically, TTFields have been proposed to align proteins possessing high intramolecular dipole moments such as tubulin dimers [6] and septins [7] which counteracts proper formation of the mitotic spindle apparatus and positioning of the cytokinetic furrow, respectively. In addition, dielectrophoretic forces in areas of non-uniform TTFields as proposed to occur at the cytokinetic furrow within the dividing cells have been postulated to trap polar macromolecules and organelles and to impair their symmetrical distribution between daughter cells. As a consequence, TTFields induce aberrant metaphase exit, improper chromosome segregation and mitotic catastrophe eventually resulting in cell death [8].

By inhibiting mitosis and cytokinesis, TTFields in particular target fast proliferating cells which results in a certain tumor specificity. Not surprisingly, besides glioblastoma, several other tumor entities such as skin, breast, pancreatic, lung, and ovarian cancer have been reported to react on TTFields in vitro $[5-7,9-14]$, in preclinical in vivo models $[5,9,12,13,15-17]$ or in clinical pilot studies $[9,18-20]$. Notably, best, i.e., most effective TTFields frequency and field strength differ between the different tumor entities with a best frequency of $200 \mathrm{kHz}$ for glioblastoma $[4,9,21]$.

Beyond impairment of mitosis and cytokinesis, TTFields reportedly lower metastatic spread of tail vein-injected B16 melanoma cells [15], and sensitize to chemo- [10], targeted [22], or radiation therapy [23]. The latter probably results from TTFields-mediated delay in DNA double strand break repair [23] possibly via downregulation of BRCA1 signaling [14]. Importantly, immunosuppression by dexamethasone seems to attenuate the response of glioblastoma patients to TTFields therapy [24] illustrating the function of the immune system in the tumor control by TTFields. Combined, these data point to a complex biological response to TTFields therapy.

Therefore, the present study aimed to identify molecular TTFields targets beyond the proposed mitotic spindle apparatus or the cytokinesis furrow. Such novel targets might be used as markers for patient stratification in terms of therapy personalization. In addition, the identification of novel molecular pathways that are triggered by TTFields and that confer resistance against the electric field therapy bears the great chance for pharmacological intervention and amplification of TTFields efficacy.

Our study placed emphasis on $\mathrm{Ca}^{2+}$ signaling and $\mathrm{Ca}^{2+}$-regulated cellular processes such as cell cycle or cell death since alternating electrical fields have been demonstrated to interfere with intracellular $\mathrm{Ca}^{2+}$ signals. For instance, voltage-activated $\mathrm{Ca}^{2+}\left(\mathrm{Ca}_{\mathrm{v}}\right)$ channels in the electrosensory organs of sharks are involved in perception of changes in the environmental electrical fields [25]. Likewise in mammalian cells, experimental or environmental alternating electric fields have been demonstrated to evoke intracellular $\mathrm{Ca}^{2+}$ signals [26-32] that may involve in particular L-type $\mathrm{Ca}_{\mathrm{v}}$ channels in the plasma membrane (for review see [33-35]). The alpha subunits of the L-type $\mathrm{Ca}^{2+}$ channels $\mathrm{Ca}_{\mathrm{v}} 1.1, \mathrm{Ca}_{\mathrm{v}} 1.2, \mathrm{Ca}_{\mathrm{v}} 1.3$, and $\mathrm{Ca}_{\mathrm{v}} 1.4$ are encoded by the CACNA1S, $-1 \mathrm{C},-1 \mathrm{D}$, and $1 \mathrm{~F}$ gene, respectively. While $\mathrm{Ca}_{\mathrm{v}} 1.1$ is mainly expressed in the skeletal muscle and $\mathrm{Ca}_{\mathrm{v}} 1.4$ restricted to retina, $\mathrm{Ca}_{\mathrm{v}} 1.2$ and $\mathrm{Ca}_{\mathrm{v}} 1.3$ are expressed in most excitable cells. In brain, $\mathrm{Ca}_{\mathrm{v}} 1.2$ and $\mathrm{Ca}_{\mathrm{v}} 1.3$ are found in the dendrites and soma of neurons where among others they are involved in the excitation-transcription coupling [36]. Notably, $\mathrm{Ca}_{\mathrm{v}}$ channels are also expressed by glioblastoma cells [37]. Potential downstream targets of $\mathrm{Ca}_{\mathrm{v}}$ are $\mathrm{Ca}^{2+}$ - activated high conductance $\mathrm{BK}_{\mathrm{Ca}}$ [38-41] and intermediate 
conductance $\mathrm{IK}_{\mathrm{Ca}}\left(\mathrm{K}_{\mathrm{Ca}} 3.1\right.$, SK4) $\mathrm{K}^{+}$channels [42-44] that have been reported to contribute to cell migration or therapy resistance of glioblastoma cells. Hence, here we analyzed TTFields-evoked modulation of cytosolic free $\mathrm{Ca}^{2+}$ concentration $\left({ }_{\text {free }}\left[\mathrm{Ca}^{2+}\right]_{i}\right.$ ) and $\mathrm{Ca}^{2+}$-dependent ion channel activity in the plasma membrane in individual human glioblastoma cells with the help of a single cell TTFields applicator disclosing a TTFields-stimulated $\mathrm{Ca}^{2+}$ entry that involves $\mathrm{Ca}_{\mathrm{v}} 1.2$ channels. In a second step, effects of TTFields on cellular DNA content, mitochondrial membrane potential $\left(\Delta \Psi_{\mathrm{m}}\right)$ and colony formation were analyzed in dependence on pharmacological $\mathrm{Ca}_{\mathrm{v}}$ blockage with the help of a TTFields cell culture applicator in order to assess cell cycle distribution, asymmetric cell division, cell death, triggering of intrinsic apoptosis, and clonogenic survival.

\section{Materials and Methods}

\subsection{Cell Culture and Transfection}

Human T98G (obtained from American Type Cell Culture Collection (ATCC, Manassas, VA, USA) and U251 (kindly provided by Dr. Luiz Penalva, San Antonio, TX, USA) glioblastoma cells were grown in 10\% fetal calf serum (FCS)-supplemented RPMI-1640 (T98G) or DMEM (4500 mg glucose/L, U251) medium. For CACNA1C knock-down, exponentially growing U251 and T98G cells were reversely transfected with a mixture of three Stealth siRNAs (Thermo Fischer Scientific, Waltham, MA, USA) specific for human CACNA1C (HSS187849, HSS187850, HSS187851) or with nt siRNA (SilencerßSelect Negative Control No. 1 siRNA, \#4390844, Ambion ${ }^{\mathrm{TM}}$, Thermo Fischer Scientific). Detached T98G and U251 cells (250,000 in 2.5 mL RPMI-1640/10\% FCS and DMEM (4500 mg glucose/L)/10\% FCS medium, respectively) were added to $500 \mu \mathrm{L}$ of pre-incubated (20 min at room temperature) Opti-MEM medium containing RNAiMAX lipofectamine $(6 \mu \mathrm{L}$, Invitrogen Life Technologies, Carlsbad, CA, USA) and siRNA (25 $\mathrm{nM}$ final concentration).

\subsection{Fura-2 Fluorescence Imaging of Cytosolic Free $\mathrm{Ca}^{2+}$ Concentration $\left({ }_{\text {free }}\left[\mathrm{Ca}^{2+}\right]_{i}\right)$}

Fluorescence measurements were performed at $37^{\circ} \mathrm{C}$ using an inverted phase-contrast microscope (Axiovert 100; Zeiss, Oberkochen, Germany). Fluorescence was evoked by a filter wheel (Visitron Systems, Puchheim, Germany)-mediated alternative excitation at 340/26 or 387/11 nm (AHF, Analysentechnik, Tübingen, Germany). Excitation and emission light was deflected by a dichromic mirror (409 nm beam splitter, AHF) into the objective (Fluar 40×/1.30 oil; Zeiss) and transmitted to the camera (Visitron Systems), respectively. Emitted fluorescence intensity was recorded at 587/35 nm (AHF). Excitation was controlled and data acquired by Metafluor computer software (Universal Imaging, Downingtown, PA, USA). The 340/380-nm fluorescence ratio was used as a measure of free $\left[\mathrm{Ca}^{2+}\right]_{i}$. Control, CACNA1C- or nt siRNA-transfected T98G and U251 cells (48 h after transfection) were incubated with fura-2/ AM (2 $\mu \mathrm{M}$ for $30 \mathrm{~min}$ at $37^{\circ} \mathrm{C}$; Molecular Probes, Goettingen, Germany) in RPMI-1640/10\% FCS and DMEM/10\% FCS medium, respectively. free $\left[\mathrm{Ca}^{2+}\right]_{i}$ was recorded at $37{ }^{\circ} \mathrm{C}$ during superfusion with $\mathrm{Ca}^{2+}$-containing $\mathrm{NaCl}$ solution (in mM: $125 \mathrm{NaCl}, 32 \mathrm{HEPES}, 5 \mathrm{KCl}$, 5 D-glucose, $1 \mathrm{MgCl}_{2}, 1 \mathrm{CaCl}_{2}$, titrated with $\mathrm{NaOH}$ to $\mathrm{pH} 7.4$ ), with $\mathrm{Ca}^{2+}$-free $\mathrm{NaCl}$ solution (in mM: $125 \mathrm{NaCl}, 32 \mathrm{HEPES}, 5 \mathrm{KCl}, 5$ D-glucose, $1 \mathrm{MgCl}_{2}, 0.6 \mathrm{EGTA}$, titrated with $\mathrm{NaOH}$ to $\mathrm{pH}$ 7.4), or with $\mathrm{Ca}^{2+}$-containing $\mathrm{NaCl}$ solution further containing the L-, $\mathrm{N}-, \mathrm{T}$-type $\mathrm{Ca}^{2+}$ channel blocker benidipine or the L-type inhibitor nifedipine (both $1 \mu \mathrm{M}$, Sigma-Aldrich, Taufkirchen, Germany) before, during and after application of TTFields $(200 \mathrm{kHz}, 0-2.5 \mathrm{~V} / \mathrm{cm})$.

\subsection{Patch Clamp Recording}

Currents of semi-confluent T98G and U251 cells were elicited by 33 voltage square pulses (700 ms each) delivered in $5 \mathrm{mV}$ increments from $0 \mathrm{mV}$ holding potential to voltages between $-80 \mathrm{mV}$ and $+80 \mathrm{mV}$ and recorded at $37^{\circ} \mathrm{C}$ in cell-attached, voltage-clamp mode by an EPC-9 amplifier (Heka, Lambrecht, Germany) using Pulse software (Heka) and an ITC-16 Interface (Instrutech, Port Washington, NY, USA). 
Clamp voltages refer to the intracellular face of the plasma membrane. Flow of positive charge out of the cells (or the counter flow of anions) is defined as positive current and depicted as upward deflection of the current tracings. Cells were superfused at $37^{\circ} \mathrm{C}$ with $\mathrm{Ca}^{2+}$-containing $\mathrm{NaCl}$ solution (see above). Borosilicate glass pipettes (4-6 M $\Omega$ pipette resistance; GC150 TF-10, Clark Medical Instruments, Pangbourne, UK) manufactured by a microprocessor-driven DMZ puller (Zeitz, Augsburg, Germany) filled with $\mathrm{Ca}^{2+}$-containing $\mathrm{NaCl}$ solution (see above) were used in combination with a STM electrical micromanipulator (Lang GmbH and Co KG, Hüttenberg, Germany). Macroscopic cell-attached currents were analyzed by averaging the currents between 100 and $700 \mathrm{~ms}$ of each square pulse. In addition to macroscopic cell-attached currents unitary current transitions were characterized for single channel conductance and open probability $\left(\mathrm{P}_{\mathrm{o}}\right)$. The latter was estimated by subtracting the zero current (i.e., the current at no apparent unitary current transition) at a given clamp voltage from the averaged macroscopic current and by dividing the difference by the amplitude of the unitary current transition and by the apparent number of active channels.

\subsection{Quantitative RT-PCR}

RNA of control, CACNA1C siRNA-, or nt siRNA-transfected U251 and T98G cells (48 h after transfection) was isolated (NucleoSpin ${ }^{\circledR}$ RNA kit, Machery-Nagel, Düren, Germany) and reversely transcribed and CACNA1A, -1B, -1C, -1D, -1E, -1G, -1H, -1I, -1S as well as housekeeper $\beta$-actin (ACTB)-, pyruvate dehydrogenase beta (PDHB)-, and glyceraldehyde-3-phosphate dehydrogenase (GAPDH)-specific fragments were amplified by the use of SYBR Green-based quantitative real-time PCR (1Step RT qPCR Green ROX L Kit, highQu, Kraichtal, Germany, and QuantiTect Primer Assays QT00054152, QT00077042, QT00053480, QT00076657, QT00063994, QT00043043, QT00075159, QT00021126, QT00000833, QT00095431, QT00031227, Qiagen, Hilden, Germany) in a Roche LightCycler ${ }^{\circledR} 480$ Instrument (Roche, Mannheim, Germany). mRNA abundances were normalized to the geometrical mean abundance of the three housekeepers.

\subsection{Analysis of Cell Cycle, DNA Degradation and Aneuploidy}

Exponentially growing T98G and U251 cells were treated for 5-7 days with TTFields ( $200 \mathrm{kHz}$, $1 \mathrm{~V} / \mathrm{cm}$ ) in the presence of benidipine ( 0 or $1 \mu \mathrm{M}$ in $0.1 \% \mathrm{DMSO})$, trypsinized, washed, and stained (30 $\mathrm{min}$ at room temperature) with propidium iodide (PI, Sigma-Aldrich) in RNase-containing phosphate-buffered saline (PBS) further containing $0.1 \%$ Na-citrate, $0.1 \%$ triton $\mathrm{X}-100$, and PI $(10 \mu \mathrm{g} / \mathrm{mL})$. For cell cycle analysis, DNA amount was recorded by flow cytometry (FACS Calibur, Becton Dickinson, Heidelberg, Germany, $488 \mathrm{~nm}$ excitation wavelength) with FL-3 (>670 nm, linear scale) emission wavelength. In addition, DNA content was monitored with FL-2 emission wavelength (585/42 nm, log scale) for determination of sub-G 1 (DNA degradation) and hyper-G (aneuploidy) populations, respectively. Data were analyzed with the FCS Express 3 software (De Novo Software, Los Angeles, CA, USA).

\subsection{Determination of Inner Mitochondrial Membrane Potential $\left(\Delta \Psi_{m}\right)$}

TTFields-treated (5-7 days, $200 \mathrm{kHz}, 1 \mathrm{~V} / \mathrm{cm}$ ) and benidipine-co-treated (0 or $1 \mu \mathrm{M}$ in $0.1 \%$ DMSO) T98G and U251 cells were trypsinized, washed, and incubated for $30 \mathrm{~min}$ at room temperature in $\mathrm{Ca}^{2+}$-containing $\mathrm{NaCl}$ solution (see above) containing the $\Delta \Psi_{\mathrm{m}}$-specific dye tetramethylrhodamine ethyl ester perchlorate (TMRE, $25 \mathrm{nM}$, Invitrogen, Karlsruhe, Germany). TMRE-specific fluorescence was measured by flow cytometry with FL-2 $(585 / 42 \mathrm{~nm})$ emission wavelength.

\subsection{Colony Formation Assay}

To test for clonogenic survival, T98G and U251 were pre-plated (600 cells/well in 12-well plates), co-incubated with benidipine ( 0 or $3 \mu \mathrm{M}$ in $0.3 \%$ DMSO) and subjected to TTFields ( $200 \mathrm{kHz}, 1 \mathrm{~V} / \mathrm{cm}$ ) for 5-7 days and further grown for 10-14 days in the continuous presence of benidipine. Thereafter, clusters of $\geq 50$ cells were defined as colonies and counted manually after fixation and Coomassie 
staining. The plating efficiency was defined by dividing the number of colonies by the number of plated cells. Survival fractions were calculated by dividing the plating efficiency of the TTFields-treated cells by those of the TTFields-untreated vehicle controls.

\subsection{Statistics}

Data are given as means \pm standard error (SE). Probability $(p)$ of statistical significance was estimated with two-tailed $t$-test or Welch-corrected two-tailed $t$-test where appropriate. $p$ values of $p \leq 0.05$ ( 2 samples) or $n p \leq 0.05$ (> 2 samples) was assumed to be significantly different with $n=$ number of pair wise comparisons in multiple testing (Bonferroni correction).

\section{Results}

To identify molecular TTFields targets, a TTFields single cell applicator (Figure 1) was constructed and connected to a function generator. Attached to the stage of an inverted microscope, the TTFields single cell applicator allowed application of electromagnetic sine waves of variable amplitude and frequency to individual cells. TTFields were applied parallel to the plane of the cell layer in a conductive manner via $\mathrm{Ag} / \mathrm{AgCl}$ electrodes. Here, the only difference to a capacitive TTFields injection (as applied to the patients) is that in the conductive situation possibly biological active Ag ions may accumulate in the cell bathing solution predominantly at the electrode/solution interface. This, however, was prevented by constant superfusion of the cells that guaranteed fast bath solution exchange. The function generator was set to $200 \mathrm{kHz}$ sine waves and the output adjusted to electric field strength of $0.25-2.5 \mathrm{~V} / \mathrm{cm}$ measured in the bath solution between the two electrodes (Figure 1C).
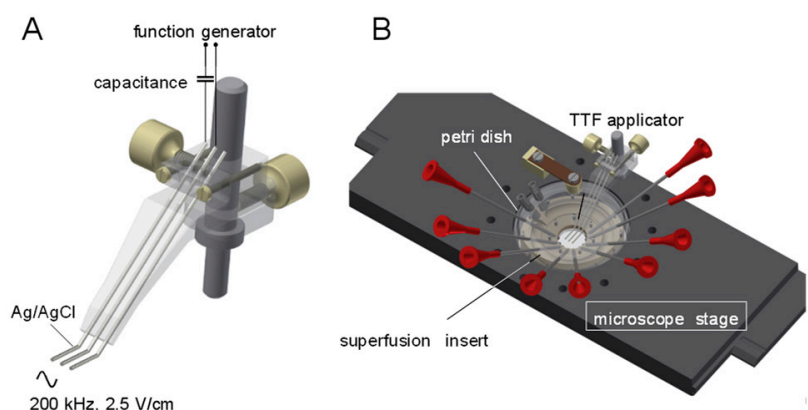

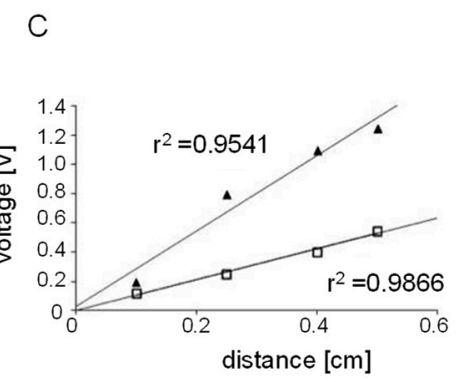

Figure 1. Single cell TTFields applicator. (A) Drawing of the applicator. TTFields are applied conductively by two $\mathrm{Ag} / \mathrm{AgCl}$ electrodes connected via a capacitance (to avoid flow of offset direct current) to a function generator (3rd electrode was originally designed for a parallel real-time $0 \mathrm{~V} / \mathrm{cm}$-field strength control but not used). (B) Positioning of the TTFields applicator, Petri dish, and superfusion/heating insert at the stage of an inverted microscope. TTFields application and cell recording were performed at $37^{\circ} \mathrm{C}$ during continuous superfusion with bath solution. Field strength in the bath solution between both application electrodes at the dish bottom was controlled by the use of two $\mathrm{Ag} / \mathrm{AgCl}$ recording electrodes. (C) Recorded voltages (peak to peak) within the TTFields at different distances. TTFields field strength was adjusted to $2.5 \mathrm{~V} / \mathrm{cm}$ (closed triangles) and $1 \mathrm{~V} / \mathrm{cm}$ (open squares) in $\mathrm{NaCl}$ solution, respectively. Recorded voltages were fitted by linear regression. The obtained correlation coefficients $\left(\mathrm{r}^{2}\right)$ were $\mathrm{r}^{2}>0.9$ suggesting a homogeneous distribution of the alternating electric fields between the applicator electrodes.

Since low alternating electric fields have been reported to interfere with intracellular $\mathrm{Ca}^{2+}$ signaling (see Section 1) we first assessed TTFields-induced changes in intracellular free $\mathrm{Ca}^{2+}$ concentration $\left({ }_{\text {free }}\left[\mathrm{Ca}^{2+}\right]_{\mathrm{i}}\right.$ ) by ratiometric fura- $2 \mathrm{Ca}^{2+}$ imaging. As a result, acute application of TTFields to U251 and T98G glioblastoma cells induced a long-lasting increase in free $\left[\mathrm{Ca}^{2+}\right]_{\mathrm{i}}$ in an electric field intensity $(0.25-2.5 \mathrm{~V} / \mathrm{cm})$-dependent manner (Figure $2 \mathrm{~A}, \mathrm{~B})$. In particular, free $\left[\mathrm{Ca}^{2+}\right]_{\mathrm{i}}$ continued to rise for more than $10 \mathrm{~min}$ after switching off the TTFields stimulation. 

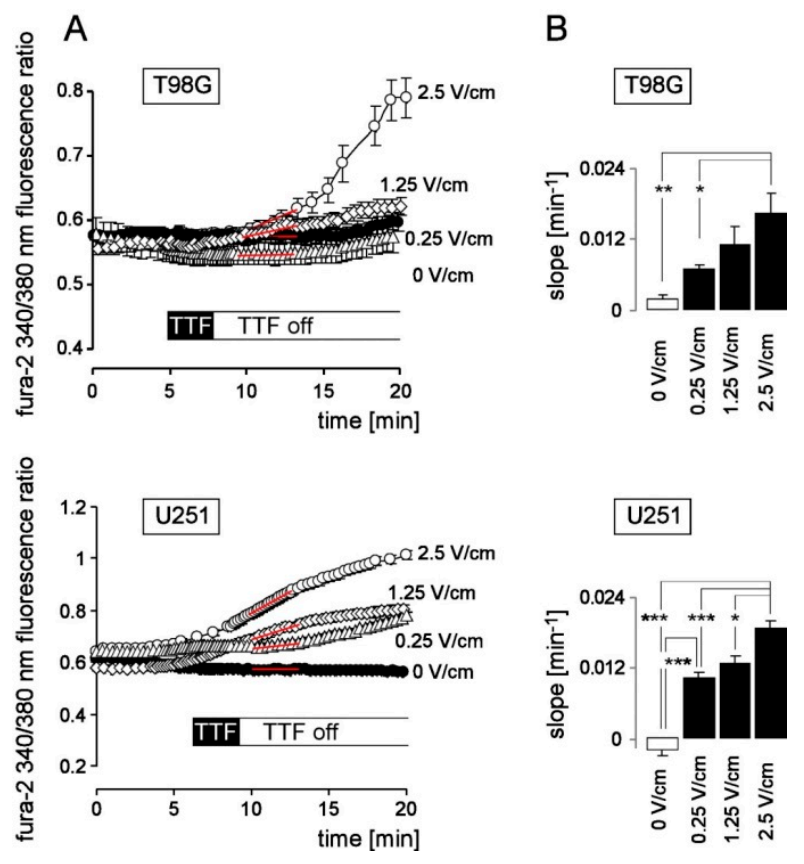

Figure 2. TTFields induce $\mathrm{Ca}^{2+}$ signals in $\mathrm{U} 251$ and T98G human glioblastoma cells in a dose-dependent manner. (A) Time course of mean ( \pm SE; $n=8-17)$ fura-2 $340 / 380 \mathrm{~nm}$ fluorescence ratio as a measure of free $\left[\mathrm{Ca}^{2+}\right]_{\mathrm{i}}$ recorded in T98G (top) and U251 cells (bottom) during superfusion with $1 \mathrm{mM}$ $\mathrm{Ca}^{2+}$-containing NaCl-solution before, during and after application of 0 (control), $0.25,1.25$, or $2.5 \mathrm{~V} / \mathrm{cm}$ TTFields (200 kHz) field strength for $3 \mathrm{~min}$. (B) Mean $( \pm \mathrm{SE} ; n=8-55)$ slope (as indicated by red lines in (A) of the TTFields-induced increase in fura-2 $340 / 380 \mathrm{~nm}$ fluorescence ratio as calculated for U251 (left), and T98G (right) cells. * ${ }^{* *}$ and ${ }^{* * *}$ in (B) indicate $6 p \leq 0.05,6 p \leq 0.01$, and $6 p \leq 0.001$, respectively, (Welch)-corrected t-test and Bonferroni correction for 6 pairwise comparisons.

To test for functional significance of this TTFields-induced rise in free $\left[\mathrm{Ca}^{2+}\right]_{\mathrm{i}}$, functionality of $\mathrm{Ca}^{2+}$-activated $\mathrm{K}^{+}$channels in the plasma membrane was monitored shortly before and directly after TTFields application $(2.5 \mathrm{~V} / \mathrm{cm}$ for $1-3 \mathrm{~min})$ by continuous cell-attached patch-clamp recording with physiological extracellular $\mathrm{NaCl}$ solution in bath and pipette (Figure 3A).

Due to the experimental set-up with an electrical line from the function generator outside the Faraday cage to the TTFields applicator electrodes that were placed closely to the recorded cells inside the Petri dish, a high $50 \mathrm{~Hz}$ ripple superimposed the cell-attached currents. This rendered it impossible to resolve unitary current transitions generated by low or intermediate conductance ion channels. However, the "macroscopic" cell-attached currents as a measure of overall channel activity of the recorded membrane area could be analyzed. As a result, TTFields induced in both glioblastoma lines an instantaneous increase in macroscopic cell-attached outward currents at positive clamp voltages (Figure 3A-C). Moreover, in the range of the physiological membrane potential (i.e., at $0 \mathrm{mV}$ clamp voltage, see below), TTFields increased (T98G cells) or showed a trend to increase (U251) the membrane conductance of the clamped membrane area (Figure 3D) suggesting that TTFields may interfere with the physiological electrosignaling of glioblastoma cells.

Remarkably, the macroscopic currents in Figure 3B (middle, right) disclose large unitary current transitions that could be characterized in more detail (Figure 3E-G). Figure 3E shows in higher power cell-attached current tracings at three clamp voltages $(0,+20$ and $+40 \mathrm{mV})$ before (left) and after $1 \mathrm{~min}$ (middle) or $3 \mathrm{~min}$ (right) of TTFields application in T98G (top) and U251 cells (bottom). In both glioblastoma lines, TTFields stimulated the activity of a channel with a conductance in the range of $150 \mathrm{pS}$ as deduced from the channel amplitude/voltage (I/V) relationships in Figure 3F. In addition, the I/V curves in this figure extrapolate (red arrow) to a reversal potential (i.e., where the curve crosses the $x$-axis) of around $-60 \mathrm{mV}$ in T98G cells (Figure $3 \mathrm{~F}$, top) and around $-40 \mathrm{mV}$ clamp 
voltage in U251 cells (Figure 3F, bottom). In cell attached mode when recorded with a physiological (i.e., $5 \mathrm{mM} \mathrm{K}^{+}$-containing) $\mathrm{NaCl}$ pipette and bath solution, the (negative) physiological membrane potential remains unaltered and applies on top of the clamp voltage across the recorded membrane. Thus, the actual reversal potentials of the I/V curves in Figure 3F are more negative than those deduced from the clamp voltage. This is important since it suggests that the actual reversal potential of the TTFields-activated channel is close to the highly negative $\mathrm{K}^{+}$equilibrium potential indicating its $\mathrm{K}^{+}$selectivity.

A

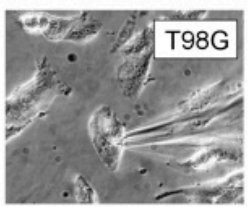

cell-attached
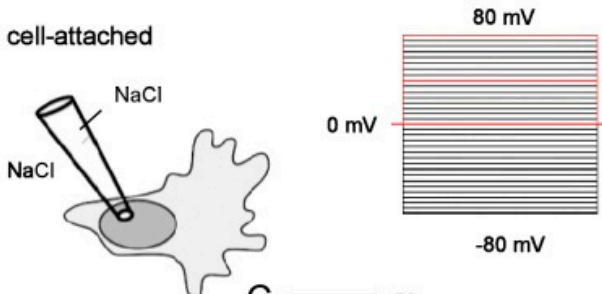

$-80 \mathrm{mV}$
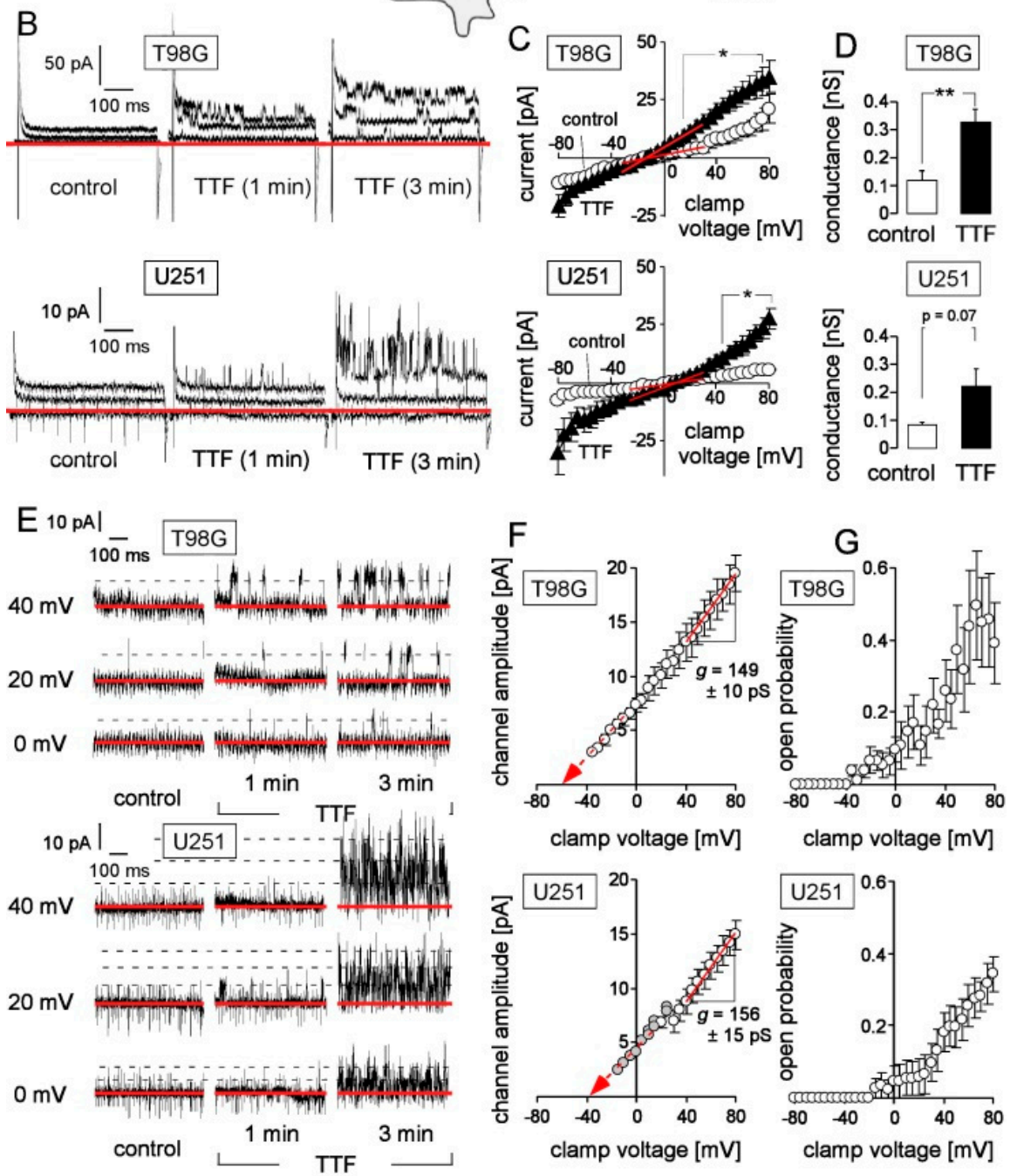

Figure 3. TTFields activate BK $\mathrm{K}^{+}$channels. (A) Macroscopic cell-attached currents were recorded from T98G (micrograph on the left) and U251 cells with the patch-clamp technique using a physiological $\mathrm{NaCl}$-rich extracellular solution in bath and pipette (middle). Currents were elicited by 33 square pulses (700 ms each) to voltages between -80 and $+80 \mathrm{mV}$ delivered from $0 \mathrm{mV}$ holding potential in 
$5 \mathrm{mV}$ increments as shown by the voltage-clamp pulse protocol on the right. (B) Cell-attached current tracings recorded as in (A) from a T98G (top) and a U251 cell (bottom) before (left), after 1 min (middle) and $3 \mathrm{~min}$ (right) TTFields $(200 \mathrm{kHz}, 2.5 \mathrm{~V} / \mathrm{cm})$ application. As illustrated by the red lines in the pulse protocol (A, right), only currents elicited by voltage steps to $0,+40$ and $+80 \mathrm{mV}$ are shown (red lines in (B) indicate the zero current). (C) Relationship between the mean ( \pm SE; $n=10-11)$ macroscopic cell-attached currents and the clamp voltage in control $(0 \mathrm{~V} / \mathrm{cm}$, open circles $)$ and TTFields (2.5 V/cm)-treated (closed triangles) T98G ( $n=10$, top) and U251 cells ( $n=6$, bottom). (D) Mean ( \pm SE; ) conductance of the clamped membrane area in T98G (top) and U251 cells (bottom) as calculated between -30 and $+30 \mathrm{mV}$ clamp voltage from the data in (C, red lines) by linear regression. * and ** in (C, and F, top) indicate $p \leq 0.05$ and $p \leq 0.01$, respectively, Welch-corrected $t$-test. The square brackets in (C) mark the voltage range, where control and TTFields-stimulated cell-attached currents differ significantly; the number in (D, bottom) indicates the $p$ value. (E) Cell-attached current tracings recorded in a T98G (top) and a U251 cell (bottom) at $0,+20$ and $+40 \mathrm{mV}$ clamp voltage before (control) and after 1 and 3 min of TTFields exposure disclosing TTFields-induced unitary outward current transitions (red lines and dashed lines indicate zero current and distinct current levels of up to three simultaneously open channels, respectively). (F,G) Relationship between channel amplitude (F) and estimated open probability (G) of the unitary current transitions in T98G (top) and U251 cells (bottom). Shown are mean ( $\pm \mathrm{SE}, n=3-5$, open symbols) or individual data (grey symbols). The red lines and red arrows in (F) depict the clamp voltage range used to calculate the single channel conductance $(g)$ by linear regression and extrapolate to the likely reversal potential, respectively.

An estimation of the open probability $\left(\mathrm{P}_{\mathrm{o}}\right)$ of this high conductance $\mathrm{K}^{+}$channel (Figure 3G) further suggests for both glioblastoma lines a depolarization-induced activation of the channel and an increase in its $P_{o}$ with increasing positive voltage. Notably, the $P_{o}$ /voltage relationship (Figure 3G, bottom) as well as the I/V curve (Figure 3F, bottom) of U251 cells were shifted by some $+20 \mathrm{mV}$ when compared to the situation in T98G cells (Figure 3F,G, top). This can be explained with a higher negative physiological membrane potential in U251 as compared to T98G cells since the higher the physiological membrane potential the more positive clamp voltage is required to reach the activation voltage of the channel. Most importantly, $\mathrm{K}^{+}$selectivity, high unitary conductance, and voltage dependence of the TTFields-induced channel were identical to the characteristics of paxilline-sensitive BK $\mathrm{K}^{+}$channels reported earlier to be highly expressed in T98G and U251 cells [45].

The I/V curves in Figure 3C especially in U251 cells also show a trend to TTFields-stimulated inward currents which, however, did not reach statistical significance. The underlying single channel activity could not be resolved because of the above mentioned limitations of our experimental set up. Along those lines, inward current transitions generated by $\mathrm{Ca}^{2+}$ channels such as low conductance voltage-gated L-type channels (e.g., upon depolarization from $0 \mathrm{mV}$ clamp voltage, i.e., from the physiological membrane potential, to $+40 \mathrm{mV}$ clamp voltage) could also not be resolved. The same holds true for $\mathrm{IK}_{\mathrm{Ca}}(\mathrm{KCa} 3.1, \mathrm{SK} 4)$-mediated outward current transitions. Nevertheless, our observations suggest that the observed TTFields-induced increase in free $\left[\mathrm{Ca}^{2+}\right]_{\mathrm{i}}$ is functionally relevant and sufficient to activate $\mathrm{BK} \mathrm{K}^{+}$channels.

Next, we characterized the TTFields-induced ${ }_{\text {free }}\left[\mathrm{Ca}^{2+}\right]_{i}$ rise in further fura- 2 experiments by analyzing its dependence on extracellular $\mathrm{Ca}^{2+}$ and its sensitivity to the $\mathrm{Ca}^{2+}$ channel inhibitors benidipine and nifedipine ( $1 \mu \mathrm{M}$, both). In both glioblastoma lines, decrease of extracellular $\mathrm{Ca}^{2+}$ by superfusion with $\mathrm{Ca}^{2+}$-free, EGTA-chelated $\mathrm{NaCl}$ solution (Figure $4 \mathrm{~A}$ ) or application of the L-, N-, T-type $\mathrm{Ca}_{\mathrm{v}}$ channel blocker benidipine in $\mathrm{Ca}^{2+}$-containing superfusate (Figure $4 \mathrm{~B}, \mathrm{C}, \mathrm{E}$ )) abolished the TTFields-induced rise in free $\left[\mathrm{Ca}^{2+}\right]_{\mathrm{i}}$. In contrast to benidipine, the L-type $\mathrm{Ca}_{\mathrm{V}}$ inhibitor nifedipine abolished only in T98G cells the TTFields-induced ${ }_{\text {free }}\left[\mathrm{Ca}^{2+}\right]_{i}$ rise completely while conferring only a partial blockage in U251 cells (Figure 4B,D,E). Notably, free $\left[\mathrm{Ca}^{2+}\right]_{i}$ started to increase for several minutes upon wash-out of benidipine and nifedipine $2 \mathrm{~min}$ and $5 \mathrm{~min}$, respectively, after switching off the TTFields stimulation (Figure $4 \mathrm{C}$ ). Together, those experiments suggest a TTFields-induced $\mathrm{Ca}^{2+}$ entry via the activation of a nifedipine-sensitive L-type $\mathrm{Ca}_{\mathrm{v}}$ channels in T98G and U251 cells and via an 
additional benidipine-sensitive and nifedipine-insensitive pathway in U251 cells. They further suggest that the TTFields effect on ${ }_{\text {free }}\left[\mathrm{Ca}^{2+}\right]_{i}$ is not simply due to electroporation of the plasma membrane. Moreover, the inhibitor wash-out experiments demonstrate that the increase in free $\left[\mathrm{Ca}^{2+}\right]_{i}$ that sustains for several minutes after end of the trigger is due to a sustained $\mathrm{Ca}^{2+}$ entry.
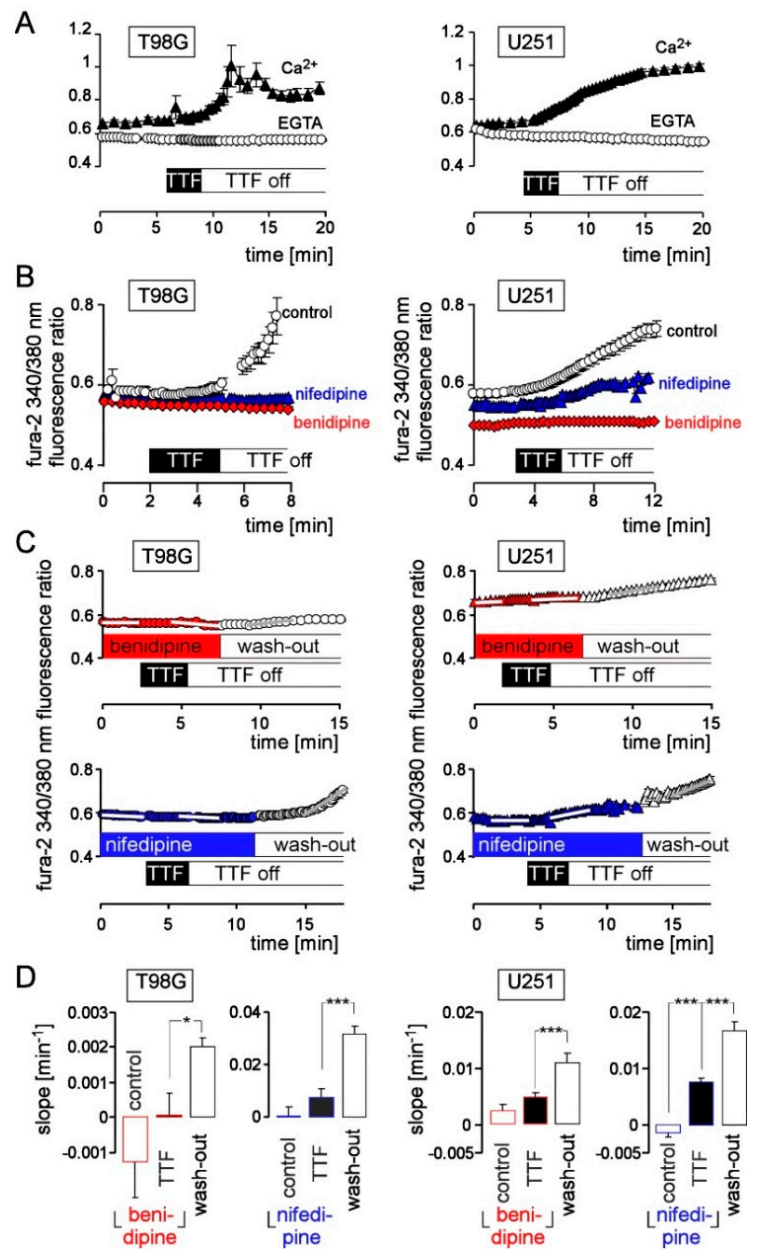

Figure 4. TTFields induce a dihydropyridine-sensitive $\mathrm{Ca}^{2+}$-entry in human glioblastoma cells. (A) Time course of TTFields $(200 \mathrm{kHz}, 2.5 \mathrm{~V} / \mathrm{cm}, 3 \mathrm{~min})$-induced changes of mean ( $\pm \mathrm{SE} ; n=8-20)$ fura-2 340/380 nm fluorescence ratio as recorded in T98G (left) and U251 (right) cells with $\mathrm{Ca}^{2+}(1 \mathrm{mM})$-containing NaCl-solution (closed triangles) and EGTA $(0.6 \mathrm{mM})$-buffered $\mathrm{Ca}^{2+}$-free $\mathrm{NaCl}$-solution (open circles). (B) Mean ( $\pm \mathrm{SE} ; n=13-20)$ fura-2 $340 / 380 \mathrm{~nm}$ fluorescence ratio recorded in T98G (left) and U251 cells (right) before, during, and after application of TTFields (200 kHz, $2.5 \mathrm{~V} / \mathrm{cm}, 3 \mathrm{~min}$ ) during continuous superfusion with $\mathrm{Ca}^{2+}$-containing $\mathrm{NaCl}$-solution (open circles), $\mathrm{Ca}^{2+}$-containing $\mathrm{NaCl}$ solution further containing $1 \mu \mathrm{M}$ benidipine (red triangles) or $1 \mu \mathrm{M}$ nifedipine (blue diamonds). (C) Mean ( \pm SE; $n=13-39$ ) fura-2 340/380 nm fluorescence ratio recorded in T98G (left) and U251 cells (right) before, during, and after application of TTFields $(200 \mathrm{kHz}, 2.5 \mathrm{~V} / \mathrm{cm}, 3 \mathrm{~min})$ during continuous superfusion with benidipine $(1 \mu \mathrm{M}$, top, red symbols) or nifedipine $(1 \mu \mathrm{M}$, bottom, blue symbols)-containing $\mathrm{NaCl}$-solution and after wash-out of the inhibitors (open symbols). (D) Mean ( \pm SE; $n=34-63$ ) slope (as indicated by white lines in (C)) of the fura-2 340/380 $\mathrm{nm}$ fluorescence ratio changes before (control), at the end and shortly after TTF-application (middle) both in the presence of benidipine (red) or nifedipine (blue) as well as after wash-out of the inhibitors. ${ }^{*}$ and ${ }^{* * *}$ in (D) indicate $3 p \leq 0.05$ and $3 p \leq 0.01$, respectively, (Welch)-corrected $t$-test and Bonferroni correction for 3 pairwise comparisons. 
Further on, we analyzed the expression of potential benidipine targets in glioblastoma. To this end, we assessed the abundance of mRNA encoding $\mathrm{Ca}^{2+}$ channels in our two human glioblastoma cell lines and in glioma resection specimens by RT-PCR and by querying the TCGA low grade glioma and provisional glioblastoma data bases, respectively. Among all tested mRNAs, the mRNA of the L-type channel CACNA1C ( $\left.\mathrm{Ca}_{\mathrm{v}} 1.2\right)$ was most abundant in T98G and U251 cells (Figure 5A). In T98G, housekeeper-normalized CACNA1C mRNA abundance exceeded that of U251 cells by almost factor of 50. Similarly, CACNA1C mRNA abundance varied considerably in resection specimens of low grade and high grade glioma (Figure 5B). Together, these data suggest CACNA1C is expressed in glioblastoma albeit at variable extent. To test for functional significance of this channel, the effect of CACNA1C knockdown (Figure 5C-F) on control and TTFields-modulated ${ }_{\text {free }}\left[\mathrm{Ca}^{2+}\right]_{i}$ in T98G and U251 cells was determined by fura-2 $\mathrm{Ca}^{2+}$ imaging. As shown in Figure 5D,E, transfection with CACNA1C siRNA decreased resting free $\left[\mathrm{Ca}^{2+}\right]_{\mathrm{i}}$ suggesting constitutive activity of $\mathrm{Ca}_{\mathrm{v}} 1.2$ in both cell lines. Moreover, CACNA1C siRNA lowered the slope of the TTFields-induced ${ }_{\text {free }}\left[\mathrm{Ca}^{2+}\right]_{\mathrm{i}}$ rise in T98G and $\mathrm{U} 251$ cells (Figure 5D,F) pointing to an involvement of $\mathrm{Ca}_{\mathrm{v}} 1.2$ in here.

A

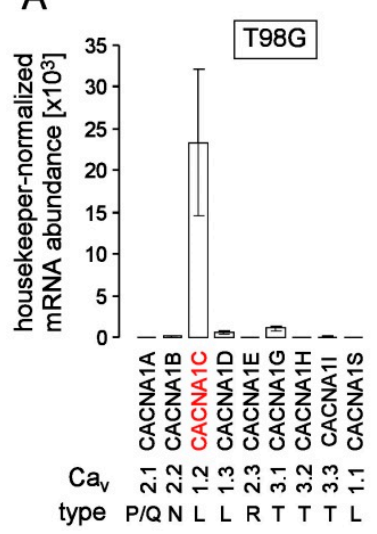

B

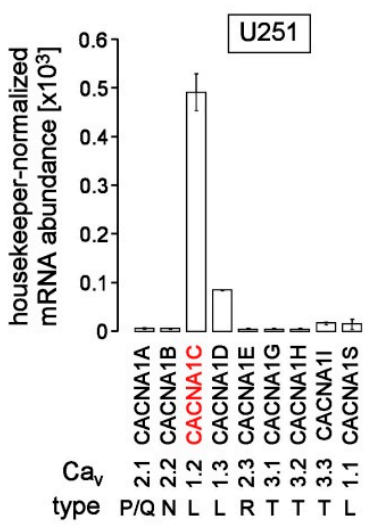

E control

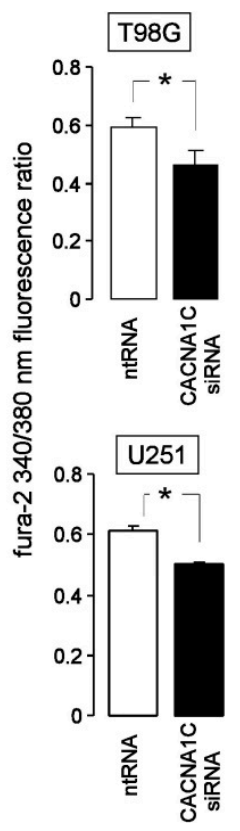

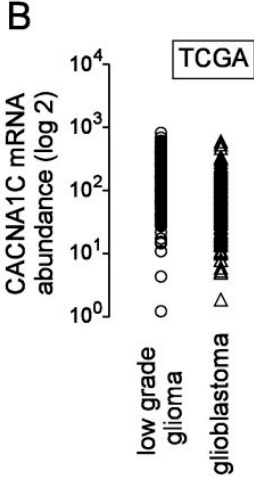

$F$ influx

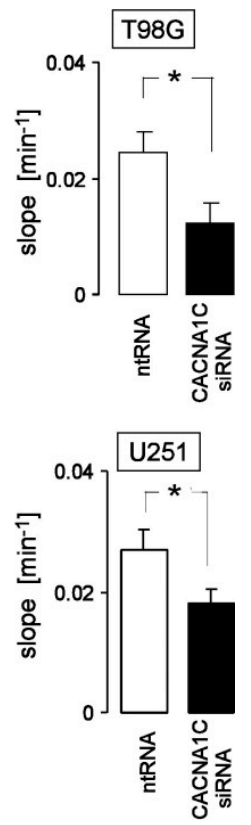

Figure 5. The voltage-gated L-type $\mathrm{Ca}^{2+}$ channel CACNA1C $\left(\mathrm{Ca}_{\mathrm{v}} 1.2\right)$ contributes to the 
TTFields-induced $\mathrm{Ca}^{2+}$ entry. (A) Mean $( \pm \mathrm{SE} ; n=3)$ housekeeper-normalized mRNA abundances $\left[\times 10^{3}\right]$ of P/Q-, N-, L-, R- and T-type $\mathrm{Ca}_{\mathrm{V}}$ channels CACNA1A, $-1 \mathrm{~B},-1 \mathrm{C},-1 \mathrm{D},-1 \mathrm{E},-1 \mathrm{G},-1 \mathrm{H},-1 \mathrm{I}$, and -1S (as indicated) in T98G (left) and U251 (right) cells as determined by real-time RT-PCR indicating expression of CACNA1C in both human glioblastoma lines. (B) CACNA1C mRNA abundances (log2 RNA seq data) of human low grade glioma (left) and glioblastoma (right) specimens vary considerably between individual tumors. The provisional Glioblastoma-Multiforme and Lower-Grade-Glioma TCGA databases (http:/ / cancergenome.nih.gov/) were queried for CACNA1C mRNA abundance in the tumor specimens via the cBIOportal Web resource [46,47]. (C) Mean $( \pm S E ; n=3)$ relative housekeeper-normalized abundance of CACNA1C mRNA in T98G (top) and U251 (bottom ) cells $48 \mathrm{~h}$ after reverse transfection with CACNA1C-siRNA (closed bars) or non-targeting RNA (ntRNA, open bars). (D) Mean ( \pm SE; $n=6-19$ ) fura-2 340/380 nm fluorescence ratio of CACNA1C siRNA (red triangles)- or ntRNA-transfected (open circles) T98G (top) and U251 cells (bottom), before, during and after application of TTFields $(200 \mathrm{kHz}, 2.5 \mathrm{~V} / \mathrm{cm}, 3-5 \mathrm{~min})$. (E,F) Mean ( \pm SE; $n=6-19)$ control ratio (E) and TTFields-induced increase in (F) fluorescence ratio of CACNA1C siRNA (red bars)- or ntRNA-transfected (open bars) T98G (top) and U251 cells (bottom). * indicates $p \leq 0.05$, Welch-corrected $t$-test).

To study the interaction of TTFields with cell biology, we developed a cell culture TTFields applicator that applied $200 \mathrm{kHz}$ sine wave electrical fields to a multi-well plate (Figure 6A). The field $(1 \mathrm{~V} / \mathrm{cm}$ peak-to-peak amplitude) was injected perpendicular to the cell layer in a capacitive manner via electrically isolated copper foils mounted below the bottom and above the lid of the multi-well plate (Figure 6B-D). To identify effects of TTFields on cell cycle and the role of $\mathrm{Ca}_{\mathrm{v}} 1.2$ herein, we co-treated T98G and U251 cells for 5-7 days with TTFields $(0$ or $1 \mathrm{~V} / \mathrm{cm})$ and benidipine $(0$ or $1 \mu \mathrm{M})$ and determined the cellular DNA content by propidium iodide staining in flow cytometry thereafter. In T98G, TTFields showed a tendency to decrease $G_{1}$ population and significantly increased $S$ and decreased $\mathrm{G}_{2}$ populations (Figure 7A top and Figure 7B, upper row) suggestive of a TTFields-induced $\mathrm{S}$ phase arrest. Benidipine alone did not affect cell cycle distribution in T98G cells but augmented the TTFields effect on $\mathrm{G}_{1}$ and $\mathrm{S}$ populations (Figure 7A top and Figure 7B, upper row). In contrast, TTFields increased $G_{1}$ and decreased $G_{2}$ population of $U 251$ cells (Figure 7A bottom and Figure 7B, lower row) indicative of a TTFields induced $G_{1}$ arrest. Unlike T98G, benidipine had no effect on cell cycle distribution of $\mathrm{U} 251$ cells (Figure 7B, lower row).

To further identify TTFields-caused asymmetric cell division, hyper-G population (i.e., cells with DNA content larger than normal diploid cells) was quantified as a measure of chromosome aneuploidy. In T98G, benidipine tended to elevate and TTFields increased hyper-G population, and both effects seemed to be additive (Figure 7C,D, top each). In U251, by contrast, TTFields tended to decrease hyper-G population while benidipine had no effect (Figure 7C,D, bottom each). Finally, sub- $\mathrm{G}_{1}$ population was analyzed as a measure of dying or dead cells with degraded DNA. In T98G, TTFields and benidipine additively induced cell death (Figure 7E,F, top each). In U251, in contrast, neither TTFields nor benidipine evoked cell death (Figure 7E,F, bottom each).

To characterize potential death pathways, we determined the inner mitochondrial membrane potential $\left(\Delta \Psi_{\mathrm{m}}\right)$ by TMRE staining in flow cytometry in T98G and U251 cells treated with TTFields $(0$ or $1 \mathrm{~V} / \mathrm{cm})$ and benidipine $(0$ or $1 \mu \mathrm{M})$ using time schedules identical to those applied for cell cycle analysis. In T98G, TTFields showed a trend to induce $\Delta \Psi_{\mathrm{m}}$ dissipation as indicated by low TMRE staining while benidipine alone had no effect. In combination, however, TTFields and benidipine evoked a doubling of cell population with dissipated $\Delta \Psi_{\mathrm{m}}$ suggesting their synergistic action (Figure 8A,B top each). In U251, in contrast, TTFields and benidipine in each case alone stimulated $\Delta \Psi_{\mathrm{m}}$ dissipation (3-fold and 1.5-fold, respectively), effects that were not additive in combined treatment (Figure 8A,B bottom each). Together, these data suggest that TTFields alone (U251) or in combination with benidipine (T98G) may trigger intrinsic apoptosis. 

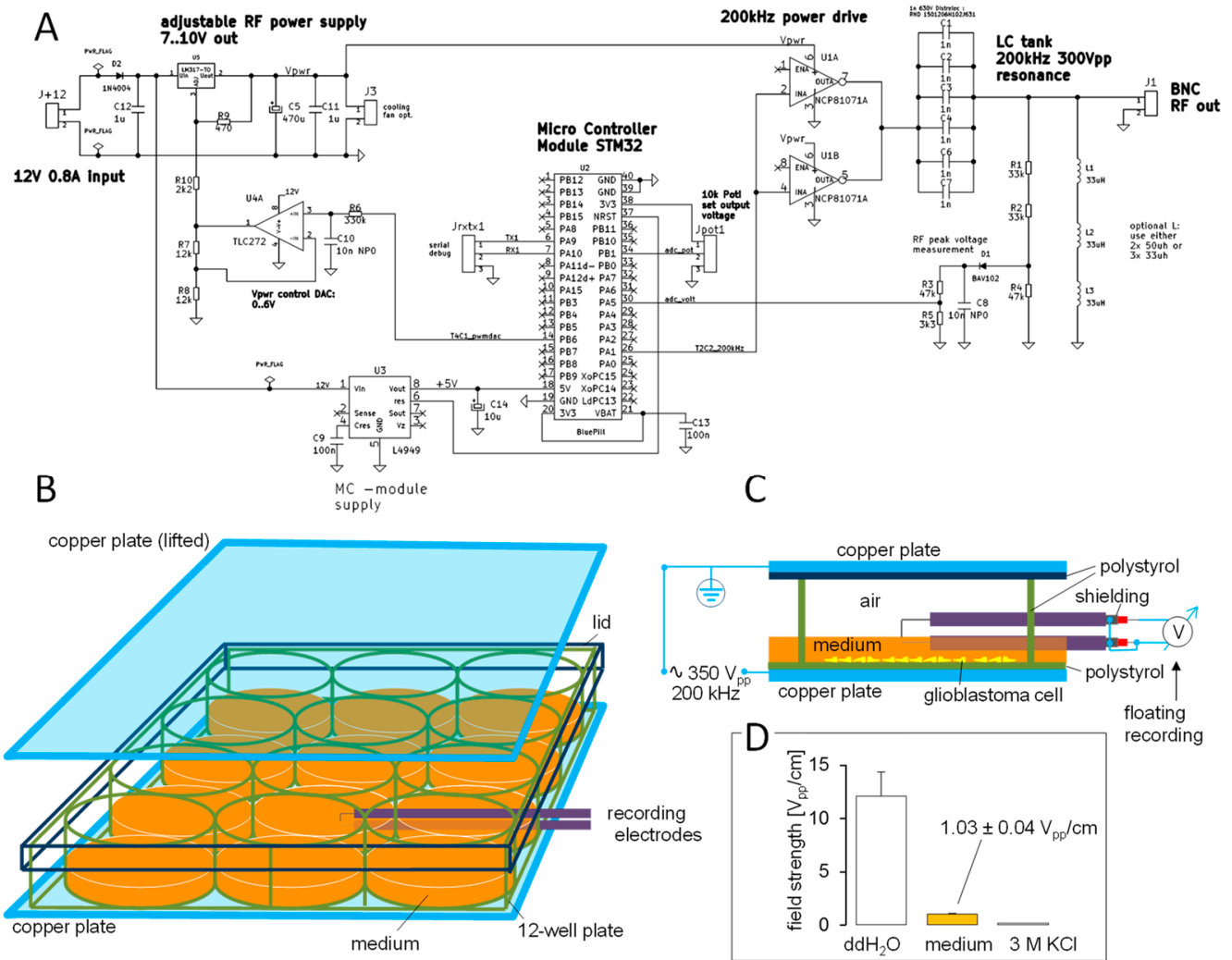

Figure 6. Cell culture TTFields applicator. (A) Circuitry of applicator. Frequency and amplitude of the $200 \mathrm{kHz}, 300 \mathrm{Vpp}$ TTFields signal is controlled by a "STM32 blue pill" micro controller module (MCM). Software was developed with the free ARDUINO programming environment. A $200 \mathrm{kHz}$ digital clock is generated by the MCM internal programmable timers. This clock is amplified by a power drive stage that delivers sufficient current and voltage to drive a $200 \mathrm{kHz}$ series LC resonance tank. LC tank resonance transforms the digital 7 to $10 \mathrm{~V}$ peak to peak drive signal into a clean sine wave of $200 \mathrm{kHz}$ and up to $350 \mathrm{~V}$ peak to peak at the RF output. Amplitude can be set by a potentiometer which controls the supply voltage of the LC-tank power drive. (B-D) Calibration of the applicator. TTFields (maximal output) are applied capacitively via two electrically isolated copper foils mounted below and above a 12-well cell culture plate. The electric field strength applying to the cells was determined under the chosen experimental conditions by the use of two shielded electrodes that were inserted laterally in a central well of a 12-well plate measuring chamber filled with $1 \mathrm{ml}$ culture medium in every well (B,C). For quality control of this measurement, the culture medium of the recorded well was replaced by media with lower $\left(\mathrm{dd}_{2} \mathrm{H}_{2} \mathrm{O}\right)$ and higher $(3 \mathrm{M} \mathrm{KCl})$ dielectric constant. As a result, electric field strength (maximal output) in cell culture medium was the range of $1 \mathrm{~V} / \mathrm{cm}$. Moreover, decreasing $\left(\mathrm{dd}_{2} \mathrm{O}\right)$ or increasing the permittivity $(3 \mathrm{M} \mathrm{KCl})$ increased and decreased, respectively, the electric field strength accordingly ( $\mathbf{D}$, data are means $\pm \mathrm{SE}, n=3-4)$. In particular, electric field strength in $\mathrm{dd}_{2} \mathrm{H}_{2} \mathrm{O}$ was about 12-times that of plasma-isotone cell culture medium (D) which suggests a relative dielectric constant of around 1000 for the cell culture medium similar to the value reported for human plasma in this wavelength range [48]. The TTFields application (5-7 days) was performed in a normal humidified $37^{\circ} \mathrm{C}$ cell culture incubator in $5 \% \mathrm{CO}_{2}$ atmosphere. Continuous TTFields application did not increase the temperature of the cultured cells. Temperature recording during up to $24 \mathrm{~h}$ of TTFields (maximal output) with a thermo-resistor directly placed in the fluid column of the cell-culture well did not disclose any TTFields-associated temperature increase $\left(36.4 \pm 0.17^{\circ} \mathrm{C}, n=5\right)$ as compared to control recording in the same set-up with switched-off TTFields $\left(36.5 \pm 0.07^{\circ} \mathrm{C}, n=3\right)$. 

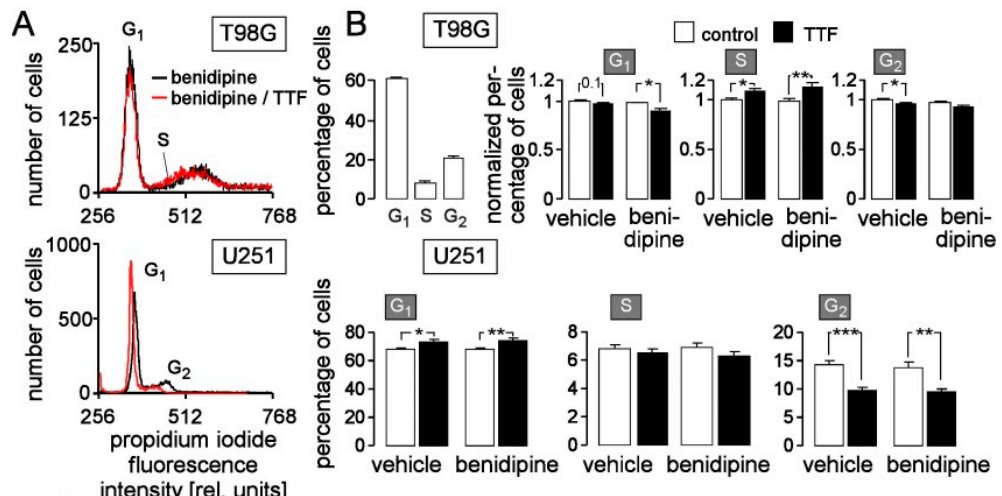

U251
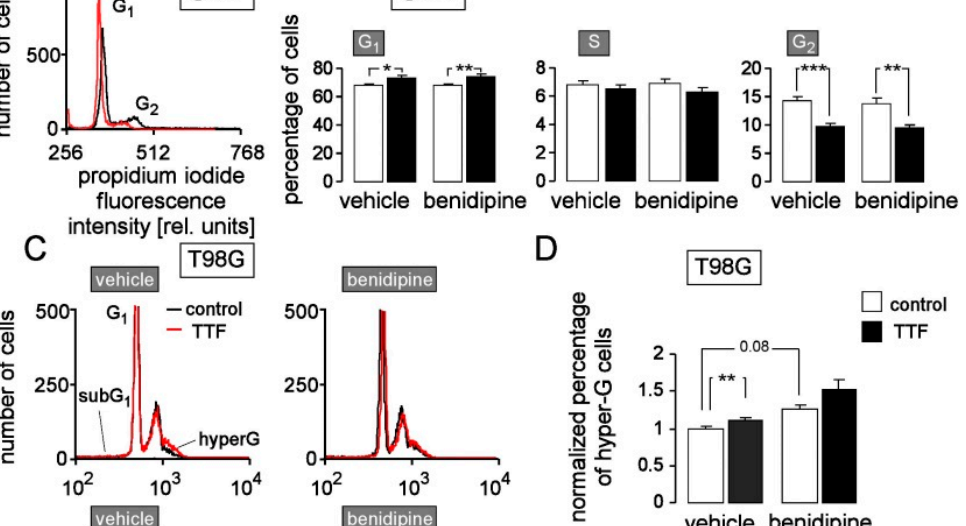

D
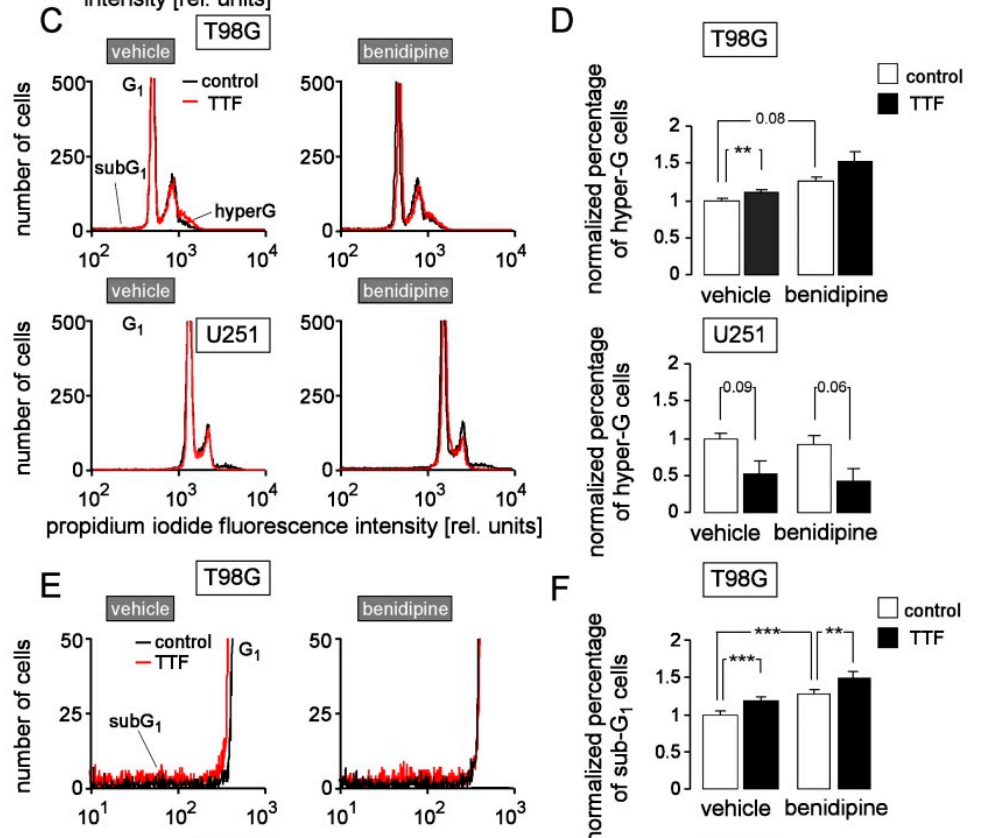

F
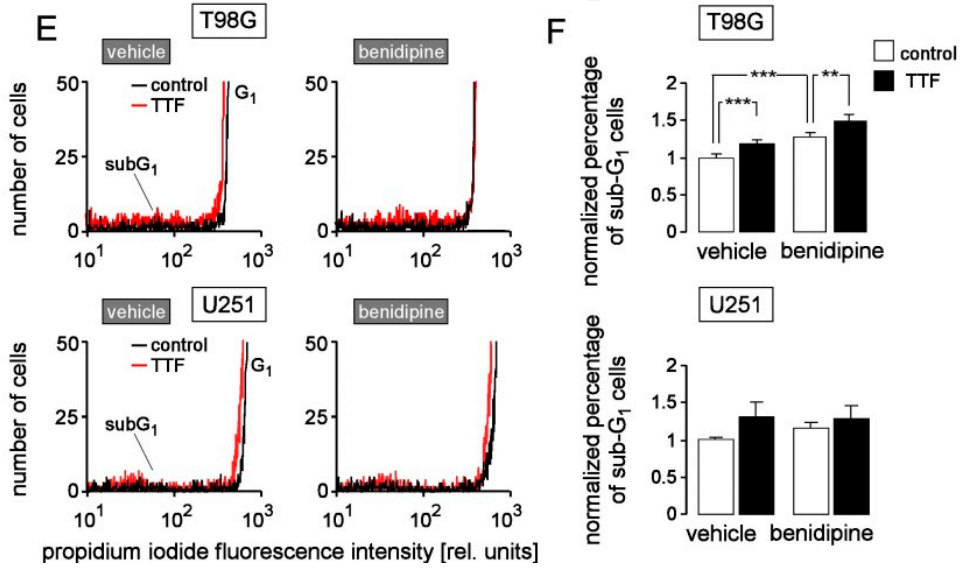

Figure 7. TTFields stimulate a $G_{1}$ or $S$ cell cycle arrest in $T 98 \mathrm{G}$ and $\mathrm{U} 251$ cells and an increase in hyper-G and sub- $\mathrm{G}_{1}$ populations in T98G cells. Benidipine $(1 \mu \mathrm{M})$ tends to augment or significantly augments these latter effects. (A,C,E) Histograms recorded by flow cytometry showing the DNA content (Nicoletti staining with propidium iodide) of T98G (top) and U251 cells (bottom) treated for 7 days with TTFields of 0 (black) or $1 \mathrm{~V} / \mathrm{cm}$ (red) field strength and benidipine ( 0 or $1 \mu \mathrm{M})$. (B,D,F) Mean $( \pm \mathrm{SE} ; n=12-22)$ percentage or normalized percentage of cells residing in $G_{2}, S$ or $G_{1}$ phase of cell cycle (B, upper line, 2nd to 4th bar diagram and lower line; the bar diagram in the upper left gives the absolute values for the control situation in T98G), cells with elevated DNA content (hyper-G population, D; absolute values in the control situation were $7.0 \pm 0.6 \%$ for T98G and $3.9 \pm 0.5 \%$ for U251), and dead cells (sub- $\mathrm{G}_{1}$ population, $\mathbf{F}$; absolute values in the control situation were $2.8 \pm 0.3 \%$ for T98G and $6.3 \pm 0.4 \%$ for $\mathrm{U} 251$ ). ${ }^{*}{ }^{* *}$ and ${ }^{* * *}$ indicate $3 p \leq 0.05,3 p \leq 0.01$, and $3 p \leq 0.001$, respectively, Welch-corrected $t$-test and Bonferroni correction for three pairwise comparisons (vehicle/control vs. benidipine/control, vehicle/control vs. vehicle/TTFields, and benidipine/control vs. benidipine/TTFields). Numbers in (B, upper line, 2nd diagram) and (D) indicate $p$ values. 

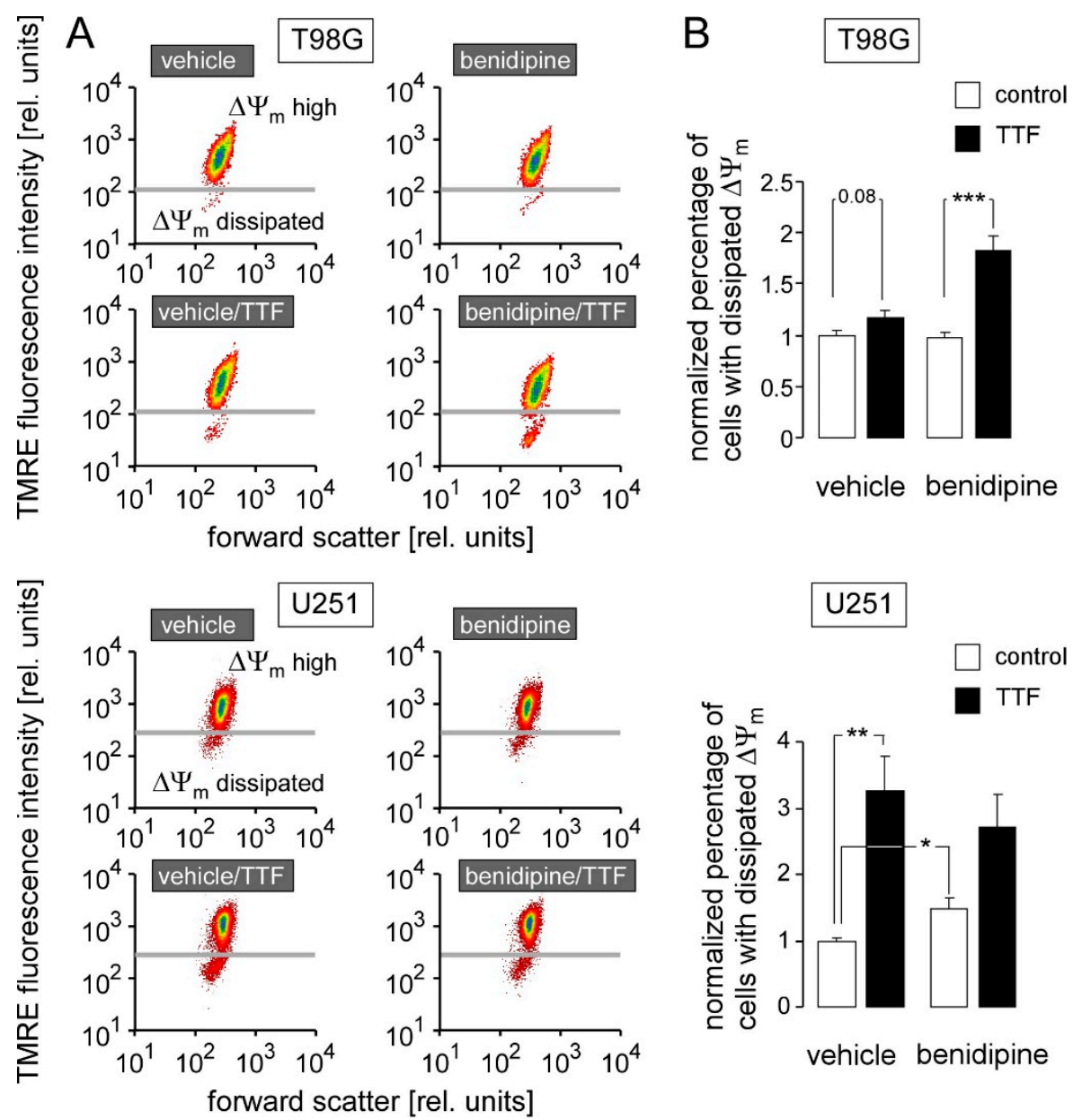

Figure 8. Benidipine augments TTFields-induced breakdown of the inner mitochondrial membrane potential $\left(\Delta \Psi_{\mathrm{m}}\right)$ in T98G cells. (A) Dot plots showing forward scatter and TMRE fluorescence intensity of T98G (top) and U251 cells (bottom) treated for 7 day with 0 (control) or $2.5 \mathrm{~V} / \mathrm{cm}$ TTFields (200 kHz) in the absence (vehicle) or presence of benidipine $(1 \mu \mathrm{M})$. (B) Mean $( \pm \mathrm{SE} ; n=12-22)$ normalized percentage of T98G (top) and U251 (bottom) cells with dissipated $\Delta \Psi_{\mathrm{m}}$ after 5-7 days of treatment with 0 (control) or $1 \mathrm{~V} / \mathrm{cm}$ TTFields (TTF, $200 \mathrm{kHz}$ ) and 0 or $1 \mu \mathrm{M}$ benidipine (absolute values of the control situation were $4.5 \pm 1.0 \%$ for T98G and $4.3 \pm 1.3 \%$ for U251). ${ }^{*},{ }^{* *}$ and ${ }^{* * *}$ indicate $3 p \leq 0.05$ and $3 p \leq 0.01$, respectively, Welch-corrected $t$-test and Bonferroni correction for three pairwise comparisons (vehicle/control vs. benidipine/control, vehicle/control vs. vehicle/TTFields, and benidipine/control vs. benidipine/ TTFields). Number in (B, top) indicates $p$ value.

Finally, we defined whether or not TTFields-induced cell death may lower clonogenic survival which is the most relevant endpoint in oncology with regard to tumor relapse after therapy. Pre-plating colony formation assay (5-7 days of TTFields with 0 or $1 \mathrm{~V} / \mathrm{cm}$ and co-incubation with 0 or $3 \mu \mathrm{M}$ benidipine followed by 10-14 days of post-incubation in the continuous presence of benidipine until formation of colonies, Figure 9A,B) suggest that both, TTFields- and benidipine monotherapies, attenuated clonogenic survival of T98G cells. In combination, the effects of both therapies tended to be additive (Figure 9A, top and Figure 9C, left). In U251, in sharp contrast, TTFields rather increased clonogenic survival and abolished the inhibitory effect of benidipine (Figure 9A, bottom and Figure 9C, right). In summary, our experiments suggest that TTFields modulate $\mathrm{Ca}^{2+}$ signaling in two human glioblastoma cell lines which involves long-lasting activation of L-type $\mathrm{Ca}_{\mathrm{v}} 1.2$ (CACNA1C) and most probably further $\mathrm{Ca}_{\mathrm{v}}$ channels and which was completely suppressed by $\mathrm{Ca}^{2+}$ channel inhibitor benidipine. Cell line-dependently, TTFields induce S (T98G) or $\mathrm{G}_{1}$ cell cycle arrest (U251), aneuploidy, and DNA degradation (T98G), triggered intrinsic apoptosis (U251), and decreased clonogenic survival 
(T98G). Importantly, in T98G cells which exhibited about 50 times higher CACNA1C mRNA abundance than U251, but not in U251 cells, benidipine aggravated TTFields-triggered cell cycle arrest, intrinsic apoptosis and DNA degradation and showed a tendency to act additively to TTFields on induction of aneuploidy and attenuation of clonogenic survival. In U251, benidipine alone triggered intrinsic apoptosis and decreased clonogenic survival. The latter was reversed by TTFields.

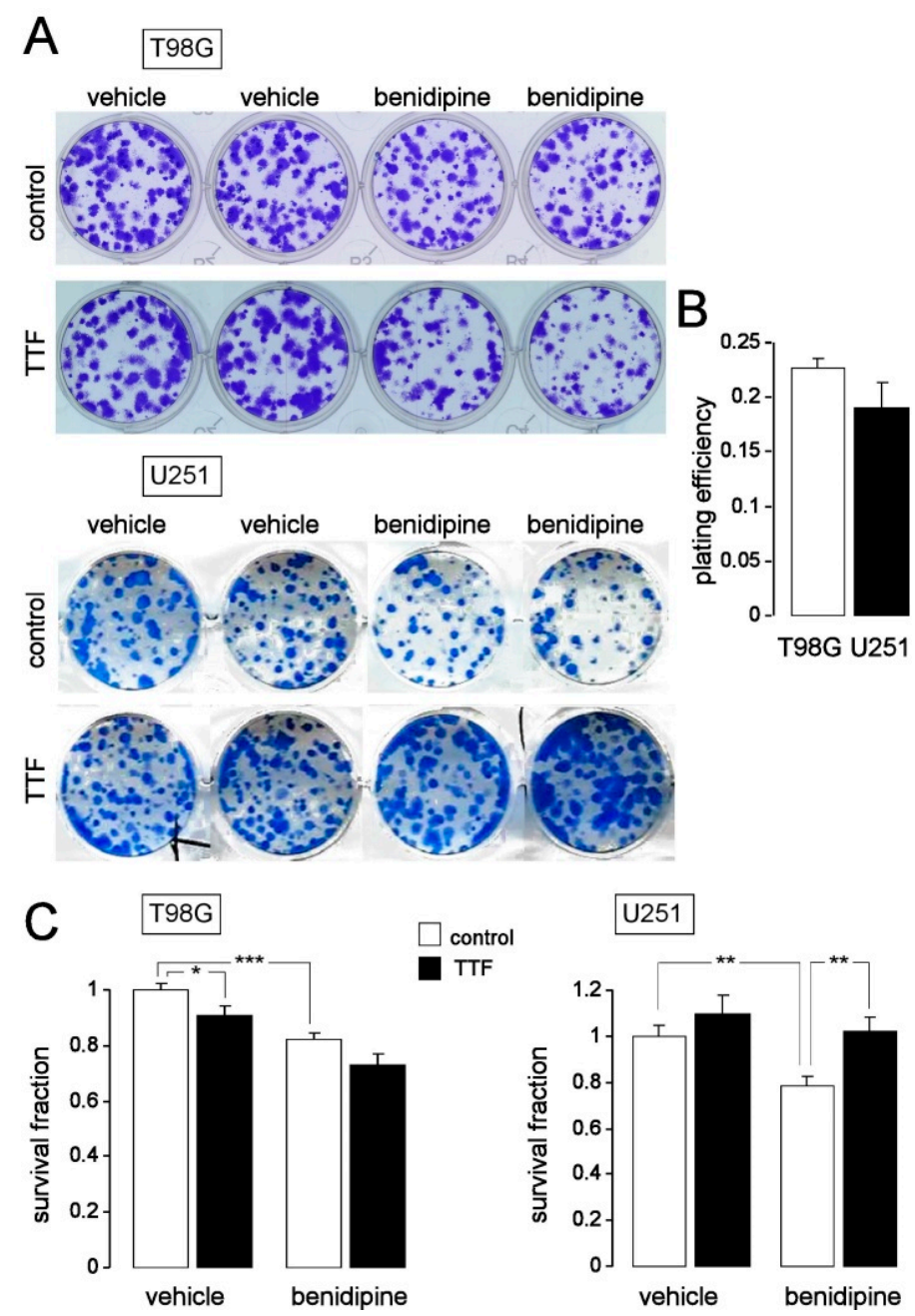

Figure 9. TTFields reduce clonogenic survival of T98G but not of U251 cells. (A) Pre-plating colony formation of T98G (top) and U251 (bottom) cells after treatment with $0 \mathrm{~V} / \mathrm{m}$ (control) or $1 \mathrm{~V} / \mathrm{m}$ TTFields field strength and co-incubation with vehicle alone or benidipine $(1 \mu \mathrm{M})$ for 7 days. Shown are cut-outs of 6-well plates with Coomassie-stained T98G (top) and U251 (bottom) colonies. (B) Mean ( \pm SE, $n=16-22$ ) plating efficiency of T98G and U251 cells. (C) Mean ( \pm SE, $n=16-24$ ) survival fractions of T98G (left) and U251 cells (right) after treatment with $0 \mathrm{~V} / \mathrm{m}$ (control) or $1 \mathrm{~V} / \mathrm{m}$ TTFields strength and co-incubation with vehicle alone or benidipine $(3 \mu \mathrm{M})$ for 7 days. Data were obtained by pre-plating colony formation assay as shown in (A). ${ }^{*}$, ** and ${ }^{* * *}$ indicate $3 p \leq 0.05,3 p \leq 0.01$, and $3 p \leq 0.001$, respectively, Welch-corrected $t$-test and Bonferroni correction for three pairwise comparisons (vehicle/control vs. benidipine/control, vehicle/control vs. vehicle/TTFields, and benidipine/control vs. benidipine/TTFields).

\section{Discussion}

In our study, TTFields impaired clonogenicity of T98G but not of U251 human glioblastoma cells indicating that individual glioblastoma may respond differentially to this electric field therapy. The inhibition of clonogenic survival of T98G cells by 5-7 days of TTFields was below 10\%. At a first glance, this effect seems to be too low to become tumor biologically relevant. However, one has to 
take into account that field direction (perpendicular and not parallel to the cell layer and field strength $(1 \mathrm{~V} / \mathrm{cm}$ instead of $3 \mathrm{~V} / \mathrm{cm})$ did not match the reported [4] optimal settings due to technical limitations of our set-up. This might hint to an underestimation of the TTFields effect by our experiments. In addition, overall treatment time of several months might lead to significantly larger effects on glioblastoma cell death and clonogenic regrowth compared to the one week application of TTFields for our in vitro experiments.

The 6-years follow up of the multicentric randomized prospective clinical trial analyzing temozolomide vs. temozolomide plus TTFields maintenance therapy suggests that in particular glioblastoma patients with methylated MGMT (O-6-methylguanine-DNA methyltransferase) promotor in the tumor benefit from TTFields therapy [2]. This might suggest that efficacy of TTFields increases with decrease of MGMT activity. In our experiments, however, the TTFields more responding line T98G has been reported to express higher MGMT activity [49] than the low TTFields responder U251 [50]. Alternatively, one might speculate that TTFields which is applied concurrently to temozolomide maintenance therapy becomes especially effective in MGMT promotor-methylated, temozolomide-sensitive cells pre-damaged by the chemotherapy. As a matter of fact, temozolomide and TTFields have been reported to synergistically accelerate cell death of irradiated glioblastoma cells in vitro, however, independently of MGMT status [51]. Additive anti-proliferative effects of temozolomide and TTFields have also been reported for temozolomide-sensitive and resistant glioblastoma stem cell-enriched primary cultures [52]. Along those lines, TTFields have been shown in vitro to improve the efficacy of radiotherapy in glioblastoma [23] and non small cell lung cancer cells [14] possibly by impairing repair of DNA double strand breaks [14]. Combined, this might suggest that TTFields are especially efficient in combination with other cytotoxic anti-cancer therapies such as radiotherapy or chemotherapy and enhance their effect as has been described for moderate locoregional hyperthermia [53]. As a matter of fact, combining mitotic checkpoint inhibition with TTFields in vitro synergistically enhance apoptotic cell death in glioblastoma cells [54].

The reported interference with DNA repair by TTFields [14] also suggests that TTFields exert additional cellular effects beyond impairment of mitotic spindle formation and cytokinesis as proposed cellular mechanisms of anti-neoplastic TTFields action (see Section 1). Evidence for the latter two came in our study from the TTFields-induced increase in T98G cell population with hyper-G DNA content as a measure of aneuploidy. Beyond that, our study identified benidipine-sensitive $\mathrm{Ca}^{2+}$ channels that comprise L-type CACNA1C $\left(\mathrm{Ca}_{\mathrm{v}} 1.2\right)$ channels as further TTFields targets. The dihydropyridine calcium channel blocker benidipine acts on L-, T-, and N-type channels. Like in the present study, alternating current electromagnetic fields (ac-EMF) such as microwave or Wi-Fi have been demonstrated in several independent studies to activate $\mathrm{Ca}^{2+}$ entry pathway in various cell types. Notably, these pathways were in part sensitive to inhibitors of voltage-gated $\mathrm{Ca}^{2+}$ channels suggesting that the ac-EMF sensitivity of voltage-gated $\mathrm{Ca}^{2+}$ channels is a general phenomenon (for review see [33]). Particularly striking was the fact that in our experiments $\mathrm{Ca}_{\mathrm{v}}$-mediated $\mathrm{Ca}^{2+}$ influx outlasted TTFields stimulation by far suggesting a constitutive activity of $\mathrm{Ca}_{\mathrm{v}}$ channels. As a matter of fact, such constitutive activity has been reported in smooth muscle cells for L-type $\mathrm{Ca}^{2+}$-channels. This constitutive activity and functional clustering of channels reportedly are mediated by protein kinase $C$ (PKC) and determine the resting free $\left[\mathrm{Ca}^{2+}\right]_{i}$ in these cells [55]. Along those lines, pulsed electrical field induced contraction of feline esophageal smooth muscle cells reportedly requires both, extracellular $\mathrm{Ca}^{2+}$ and PKC activity [56]. This might suggest that similar processes contribute to the long-lasting $\mathrm{Ca}^{2+}$ entry in TTFields-treated glioblastoma cells.

Taking into account that cell cycle [57], cell migration [38,45,57], brain infiltration [40], cell death programming [57], DNA repair and radioresistance [42,57] of glioblastoma cells have been demonstrated to be regulated by $\mathrm{Ca}^{2+}$-dependent signaling pathways [58] an interference of TTFields with glioblastoma biology can be expected. In line with this assumption, the present study demonstrated that TTFields indeed interfered with all cell biological parameters tested. 
Of note, the voltage-gated $\mathrm{Ca}^{2+}$ channel blocker benidipine did not revert the observed cellular TTFields effects indicating that these effects most probably were not induced by TTFields-triggered benidipine-sensitive $\mathrm{Ca}^{2+}$ influx. Rather, benidipine aggravated (or showed the tendency to increase) the TTFields effects in T98G cells. Unexpectedly, such a concerted action of benidipine and TTFields was not observed in U251 cells although both glioblastoma lines exhibited comparable TTFields-induced $\mathrm{Ca}^{2+}$ entries that were both completely blocked by benidipine (see Figure 4). In contrast to T98G, TTFields decreased aneuploidy and rather increased than decreased clonogenic survival in U251 again illustrating that individual glioblastomas may respond differentially to TTFields.

Irrespective of its effect in combination with TTFields, benidipine alone induced in the present study in both glioblastoma lines either DNA degradation (T98G) or $\Delta \Psi_{\mathrm{m}}$ dissipation (U251) and lowered clonogenic survival (both lines) indicating its anti-neoplastic action. Among the known benidipine targets, mRNA encoding the L-type $\mathrm{Ca}^{2+}$ channel CACNA1C $\left(\mathrm{Ca}_{\mathrm{v}} 1.2\right)$ was most abundant in both glioblastoma lines strongly suggesting that the observed benidipine effects were mediated at least in part via inhibition of CACNA1C. The functional significance of CACNA1C for the $\mathrm{Ca}^{2+}$ signaling of both glioblastoma cell lines can be deduced from the decline in resting $\mathrm{Ca}^{2+}$ concentration (i.e., control free $\left[\mathrm{Ca}^{2+}\right]_{i}$, see Figure $5 \mathrm{E}$ ) upon knockdown of CACNA1C.

The notion of a presumable general anti-neoplastic function of benidipine in glioblastoma in concert with the observed TTFields stimulation of a benidipine-sensitive target that probably counteract the TTFields effects (at least in the TTFields more responding glioblastoma cell line T98G) provides a rationale to combine alternating electric field therapy with $\mathrm{Ca}^{2+}$ antagonists even in tumors with unknown TTFields responsiveness. Benidipine, which is in clinical use in Japan and India (Coniel $^{\circledR}$; Kyowa Hakko Kirin Co., Ltd., Tokyo, Japan [59]) as anti-hypertensive drug is well tolerated. Tissue distribution in rats of orally applied benidipine indicates drug accumulation predominantly in digestive organs, mesenteric lymph nodes, liver, pancreas, urinary bladder, fat tissue, kidney and spleen [60]. The usually high penetrability of the glioblastoma blood barrier is expected to facilitate delivery of benidipine specifically to the glioblastoma while the blood brain barrier can be assumed to hamper distribution of benidipine in healthy brain parenchyma. Combined, this suggests that targeting of glioblastoma $\mathrm{Ca}^{2+}$ channels by benidipine or other FDA-approved $\mathrm{Ca}^{2+}$-antagonists such as nifedipine [61] seems to be clinically feasible.

\section{Conclusions}

TTFields act on several molecular targets/pathways thereby influencing $\mathrm{Ca}^{2+}-$ and electrosignaling, cell cycle progression, programmed cell death, and clonogenic survival of glioblastoma cells. Concerning the most relevant parameter in oncology that is the clonogenic survival, TTFields responsiveness differed markedly between the two human glioblastoma lines tested suggesting that also in the clinical situation the benefit of TTFields therapy may vary considerably between individual glioblastoma patients. Knowledge of the underlying molecular mechanisms might be used for therapy stratification in the future or for pharmacological intervention and improvement of the tumoricidal TTFields effects. One such potential approach evolves from the present study that disclosed that $\mathrm{Ca}_{\mathrm{v}}$ channel activity contributes to cellular stress response to TTFields and $\mathrm{Ca}_{\mathrm{v}}$ inhibition may augment the TTFields effects.

Author Contributions: Conceptualization, data analysis and data visualization: E.N. and S.M.H.; methodology and investigation: E.N., L.Z., K.G., L.K., U.S., and S.M.H.; software: U.S.; original draft preparation: E.N., L.Z., and S.M.H.; review and editing: D.Z., F.E., and S.M.H.; funding acquisition and supervision: S.M.H.

Funding: This research was supported by a grant of the German Cancer Aid (grant number 70112872/70113144).

Acknowledgments: We thank Heidrun Faltin for excellent technical assistance, Andreas Hönes for constructing the TTF single cell applicator, and Savas Tsitsekidis for the help with the TTFields calibration.

Conflicts of Interest: D.Z. has research collaborations with Elekta, Philips, Siemens and Dr. Sennewald. S.M.H. with Novocure, F.E. with Merck KGaA. The other authors declare no conflict of interest. 


\section{References}

1. Stupp, R.; Wong, E.T.; Kanner, A.A.; Steinberg, D.; Engelhard, H.; Heidecke, V.; Kirson, E.D.; Taillibert, S.; Liebermann, F.; Dbaly, V.; et al. NovoTTF-100A versus physician's choice chemotherapy in recurrent glioblastoma: A randomised phase III trial of a novel treatment modality. Eur. J. Cancer (Oxford, England: 1990) 2012, 48, 2192-2202. [CrossRef] [PubMed]

2. Stupp, R.; Taillibert, S.; Kanner, A.; Read, W.; Steinberg, D.; Lhermitte, B.; Toms, S.; Idbaih, A.; Ahluwalia, M.S.; Fink, K.; et al. Effect of Tumor-Treating Fields Plus Maintenance Temozolomide vs Maintenance Temozolomide Alone on Survival in Patients With Glioblastoma: A Randomized Clinical Trial. JAMA 2017, 318, 2306-2316. [CrossRef] [PubMed]

3. Lacouture, M.E.; Davis, M.E.; Elzinga, G.; Butowski, N.; Tran, D.; Villano, J.L.; DiMeglio, L.; Davies, A.M.; Wong, E.T. Characterization and management of dermatologic adverse events with the NovoTTF-100A System, a novel anti-mitotic electric field device for the treatment of recurrent glioblastoma. Semin. Oncol. 2014, 41 (Suppl. 4), S1-S14. [CrossRef]

4. Kirson, E.D.; Gurvich, Z.; Schneiderman, R.; Dekel, E.; Itzhaki, A.; Wasserman, Y.; Schatzberger, R.; Palti, Y. Disruption of cancer cell replication by alternating electric fields. Cancer Res. 2004, 64, 3288-3295. [CrossRef] [PubMed]

5. Giladi, M.; Schneiderman, R.S.; Porat, Y.; Munster, M.; Itzhaki, A.; Mordechovich, D.; Cahal, S.; Kirson, E.D.; Weinberg, U.; Palti, Y. Mitotic disruption and reduced clonogenicity of pancreatic cancer cells in vitro and in vivo by tumor treating fields. Pancreatology 2014, 14, 54-63. [CrossRef] [PubMed]

6. Giladi, M.; Schneiderman, R.S.; Voloshin, T.; Porat, Y.; Munster, M.; Blat, R.; Sherbo, S.; Bomzon, Z.; Urman, N.; Itzhaki, A.; et al. Mitotic Spindle Disruption by Alternating Electric Fields Leads to Improper Chromosome Segregation and Mitotic Catastrophe in Cancer Cells. Sci. Rep. 2015, 5, 18046. [CrossRef] [PubMed]

7. Gera, N.; Yang, A.; Holtzman, T.S.; Lee, S.X.; Wong, E.T.; Swanson, K.D. Tumor treating fields perturb the localization of septins and cause aberrant mitotic exit. PLoS ONE 2015, 10, e0125269. [CrossRef]

8. Gutin, P.H.; Wong, E.T. Noninvasive application of alternating electric fields in glioblastoma: A fourth cancer treatment modality. Am. Soc. Clin. Oncol. Educ. Book. 2012, 32, 126-131. [CrossRef]

9. Kirson, E.D.; Dbaly, V.; Tovarys, F.; Vymazal, J.; Soustiel, J.F.; Itzhaki, A.; Mordechovich, D.; Steinberg-Shapira, S.; Gurvich, Z.; Schneiderman, R.; et al. Alternating electric fields arrest cell proliferation in animal tumor models and human brain tumors. Proc. Natl. Acad. Sci. USA 2007, 104, 10152-10157. [CrossRef]

10. Kirson, E.D.; Schneiderman, R.S.; Dbaly, V.; Tovarys, F.; Vymazal, J.; Itzhaki, A.; Mordechovich, D.; Gurvich, Z.; Shmueli, E.; Goldsher, D.; et al. Chemotherapeutic treatment efficacy and sensitivity are increased by adjuvant alternating electric fields (TTFields). BMC Med. Phys. 2009, 9, 1. [CrossRef]

11. Schneiderman, R.S.; Shmueli, E.; Kirson, E.D.; Palti, Y. TTFields alone and in combination with chemotherapeutic agents effectively reduce the viability of MDR cell sub-lines that over-express ABC transporters. BMC Cancer 2010, 10, 229. [CrossRef] [PubMed]

12. Giladi, M.; Weinberg, U.; Schneiderman, R.S.; Porat, Y.; Munster, M.; Voloshin, T.; Blatt, R.; Cahal, S.; Itzhaki, A.; Onn, A.; et al. Alternating electric fields (tumor-treating fields therapy) can improve chemotherapy treatment efficacy in non-small cell lung cancer both in vitro and in vivo. Semin. Oncol. 2014, 41 (Suppl. 6), S35-S41. [CrossRef]

13. Voloshin, T.; Munster, M.; Blatt, R.; Shteingauz, A.; Roberts, P.C.; Schmelz, E.M.; Giladi, M.; Schneiderman, R.S.; Zeevi, E.; Porat, Y.; et al. Alternating electric fields (TTFields) in combination with paclitaxel are therapeutically effective against ovarian cancer cells in vitro and in vivo. Int. J. Cancer 2016, 139, 2850-2858. [CrossRef] [PubMed]

14. Karanam, N.K.; Srinivasan, K.; Ding, L.; Sishc, B.; Saha, D.; Story, M.D. Tumor-treating fields elicit a conditional vulnerability to ionizing radiation via the downregulation of BRCA1 signaling and reduced DNA double-strand break repair capacity in non-small cell lung cancer cell lines. Cell Death Dis. 2017, 8, e2711. [CrossRef] [PubMed]

15. Kirson, E.D.; Giladi, M.; Gurvich, Z.; Itzhaki, A.; Mordechovich, D.; Schneiderman, R.S.; Wasserman, Y.; Ryffel, B.; Goldsher, D.; Palti, Y. Alternating electric fields (TTFields) inhibit metastatic spread of solid tumors to the lungs. Clin. Exp. Metastasis 2009, 26, 633-640. [CrossRef] [PubMed] 
16. Castellvi, Q.; Ginesta, M.M.; Capella, G.; Ivorra, A. Tumor growth delay by adjuvant alternating electric fields which appears non-thermally mediated. Bioelectrochemistry 2015, 105, 16-24. [CrossRef] [PubMed]

17. Li, J.; Guo, C.; Wang, Z.; Gao, K.; Shi, X.; Liu, J. Electrical stimulation towards melanoma therapy via liquid metal printed electronics on skin. Clin. Transl. Med. 2016, 5, 21. [CrossRef]

18. Salzberg, M.; Kirson, E.; Palti, Y.; Rochlitz, C. A pilot study with very low-intensity, intermediate-frequency electric fields in patients with locally advanced and/or metastatic solid tumors. Onkologie 2008, 31, 362-365. [CrossRef]

19. Pless, M.; Droege, C.; von Moos, R.; Salzberg, M.; Betticher, D. A phase I/II trial of Tumor Treating Fields (TTFields) therapy in combination with pemetrexed for advanced non-small cell lung cancer. Lung Cancer 2013, 81, 445-450. [CrossRef]

20. Vergote, I.; von Moos, R.; Manso, L.; Van Nieuwenhuysen, E.; Concin, N.; Sessa, C. Tumor Treating Fields in combination with paclitaxel in recurrent ovarian carcinoma: Results of the INNOVATE pilot study. Gynecol. Oncol. 2018, 150, 471-477. [CrossRef]

21. Porat, Y.; Giladi, M.; Schneiderman, R.S.; Blat, R.; Shteingauz, A.; Zeevi, E.; Munster, M.; Voloshin, T.; Kaynan, N.; Tal, O.; et al. Determining the Optimal Inhibitory Frequency for Cancerous Cells Using Tumor Treating Fields (TTFields). J. Vis. Exp. 2017. [CrossRef] [PubMed]

22. Meletath, S.K.; Pavlick, D.; Brennan, T.; Hamilton, R.; Chmielecki, J.; Elvin, J.A.; Palma, N.; Ross, J.S.; Miller, V.A.; Stephens, P.J.; et al. Personalized Treatment for a Patient With a BRAF V600E Mutation Using Dabrafenib and a Tumor Treatment Fields Device in a High-Grade Glioma Arising From Ganglioglioma. J. Natl. Compr. Cancer Netw. 2016, 14, 1345-1350. [CrossRef]

23. Giladi, M.; Munster, M.; Schneiderman, R.S.; Voloshin, T.; Porat, Y.; Blat, R.; Zielinska-Chomej, K.; Haag, P.; Bomzon, Z.; Kirson, E.D.; et al. Tumor treating fields (TTFields) delay DNA damage repair following radiation treatment of glioma cells. Radiat. Oncol. 2017, 12, 206. [CrossRef] [PubMed]

24. Wong, E.T.; Lok, E.; Gautam, S.; Swanson, K.D. Dexamethasone exerts profound immunologic interference on treatment efficacy for recurrent glioblastoma. Br. J. Cancer 2015, 113, 232-241. [CrossRef] [PubMed]

25. Bellono, N.W.; Leitch, D.B.; Julius, D. Molecular basis of ancestral vertebrate electroreception. Nature 2017, 543, 391-396. [CrossRef]

26. Morgado-Valle, C.; Verdugo-Diaz, L.; Garcia, D.E.; Morales-Orozco, C.; Drucker-Colin, R. The role of voltage-gated $\mathrm{Ca}^{2+}$ channels in neurite growth of cultured chromaffin cells induced by extremely low frequency (ELF) magnetic field stimulation. Cell Tissue Res. 1998, 291, 217-230. [CrossRef]

27. Grassi, C.; D’Ascenzo, M.; Torsello, A.; Martinotti, G.; Wolf, F.; Cittadini, A.; Azzena, G.B. Effects of $50 \mathrm{~Hz}$ electromagnetic fields on voltage-gated $\mathrm{Ca}^{2+}$ channels and their role in modulation of neuroendocrine cell proliferation and death. Cell Calcium 2004, 35, 307-315. [CrossRef]

28. Piacentini, R.; Ripoli, C.; Mezzogori, D.; Azzena, G.B.; Grassi, C. Extremely low-frequency electromagnetic fields promote in vitro neurogenesis via upregulation of $\mathrm{Ca}(\mathrm{v}) 1$-channel activity. J. Cell. Physiol. 2008, 215, 129-139. [CrossRef]

29. Li, Y.; Yan, X.; Liu, J.; Li, L.; Hu, X.; Sun, H.; Tian, J. Pulsed electromagnetic field enhances brain-derived neurotrophic factor expression through L-type voltage-gated calcium channel- and Erk-dependent signaling pathways in neonatal rat dorsal root ganglion neurons. Neurochem. Int. 2014, 75, 96-104. [CrossRef]

30. Luo, F.L.; Yang, N.; He, C.; Li, H.L.; Li, C.; Chen, F.; Xiong, J.X.; Hu, Z.A.; Zhang, J. Exposure to extremely low frequency electromagnetic fields alters the calcium dynamics of cultured entorhinal cortex neurons. Environ. Res. 2014, 135, 236-246. [CrossRef]

31. Burke, R.C.; Bardet, S.M.; Carr, L.; Romanenko, S.; Arnaud-Cormos, D.; Leveque, P.; O'Connor, R.P. Nanosecond pulsed electric fields depolarize transmembrane potential via voltage-gated $\mathrm{K}^{+}, \mathrm{Ca}^{2+}$ and TRPM8 channels in U87 glioblastoma cells. Biochim. Biophys. Acta Biomembr. 2017, 1859, 2040-2050. [CrossRef] [PubMed]

32. Kim, J.H.; Sohn, U.D.; Kim, H.G.; Kim, H.R. Exposure to 835 MHz RF-EMF decreases the expression of calcium channels, inhibits apoptosis, but induces autophagy in the mouse hippocampus. Korean J. Physiol. Pharm. 2018, 22, 277-289. [CrossRef] [PubMed]

33. Pall, M.L. Electromagnetic fields act via activation of voltage-gated calcium channels to produce beneficial or adverse effects. J. Cell Mol. Med. 2013, 17, 958-965. [CrossRef] [PubMed] 
34. Pall, M.L. Scientific evidence contradicts findings and assumptions of Canadian Safety Panel 6: Microwaves act through voltage-gated calcium channel activation to induce biological impacts at non-thermal levels, supporting a paradigm shift for microwave/lower frequency electromagnetic field action. Rev. Environ. Health 2015, 30, 99-116. [CrossRef] [PubMed]

35. Pall, M.L. Microwave frequency electromagnetic fields (EMFs) produce widespread neuropsychiatric effects including depression. J. Chem. Neuroanat. 2016, 75, 43-51. [CrossRef] [PubMed]

36. Zamponi, G.W.; Striessnig, J.; Koschak, A.; Dolphin, A.C. The Physiology, Pathology, and Pharmacology of Voltage-Gated Calcium Channels and Their Future Therapeutic Potential. Pharmacol. Rev. 2015, 67, 821-870. [CrossRef] [PubMed]

37. Zhang, Y.; Zhang, J.; Jiang, D.; Zhang, D.; Qian, Z.; Liu, C.; Tao, J. Inhibition of T-type Ca ${ }^{2+}$ channels by endostatin attenuates human glioblastoma cell proliferation and migration. Br. J. Pharmacol. 2012, 166, 1247-1260. [CrossRef]

38. Steinle, M.; Palme, D.; Misovic, M.; Rudner, J.; Dittmann, K.; Lukowski, R.; Ruth, P.; Huber, S.M. Ionizing radiation induces migration of glioblastoma cells by activating BK $\mathrm{K}^{+}$channels. Radiother. Oncol. 2011, 101, 122-126. [CrossRef]

39. Catacuzzeno, L.; Caramia, M.; Sforna, L.; Belia, S.; Guglielmi, L.; D’Adamo, M.C.; Pessia, M.; Franciolini, F. Reconciling the discrepancies on the involvement of large-conductance $\mathrm{Ca}^{2+}$-activated $\mathrm{K}$ channels in glioblastoma cell migration. Front. Cell. Neurosci. 2015, 9, 152. [CrossRef]

40. Edalat, L.; Stegen, B.; Klumpp, L.; Haehl, E.; Schilbach, K.; Lukowski, R.; Kühnle, M.; Bernhardt, G.; Buschauer, A.; Zips, D.; et al. BK K ${ }^{+}$channel blockade inhibits radiation-induced migration/brain infiltration of glioblastoma cells. Oncotarget 2016, 7, 14259-14278. [CrossRef]

41. Rosa, P.; Catacuzzeno, L.; Sforna, L.; Mangino, G.; Carlomagno, S.; Mincione, G.; Petrozza, V.; Ragona, G.; Franciolini, F.; Calogero, A. BK channels blockage inhibits hypoxia-induced migration and chemoresistance to cisplatin in human glioblastoma cells. J. Cell. Physiol. 2018, 233, 6866-6877. [CrossRef] [PubMed]

42. Stegen, B.; Butz, L.; Klumpp, L.; Zips, D.; Dittmann, K.; Ruth, P.; Huber, S.M. Ca ${ }^{2+}$-Activated IK K ${ }^{+}$Channel Blockade Radiosensitizes Glioblastoma Cells. Mol. Cancer Res. 2015, 13, 1283-1295. [CrossRef] [PubMed]

43. Klumpp, L.; Sezgin, E.C.; Skardelly, M.; Eckert, F.; Huber, S.M. KCa3.1 channels and glioblastoma: In vitro studies. Curr. Neuropharmacol. 2018, 16, 627-635. [CrossRef] [PubMed]

44. Catacuzzeno, L.; Franciolini, F. Role of KCa3.1 Channels in Modulating $\mathrm{Ca}^{2+}$ Oscillations during Glioblastoma Cell Migration and Invasion. Int. J. Mol. Sci. 2018, 19. [CrossRef] [PubMed]

45. Eckert, M.; Klumpp, L.; Huber, S.M. Cellular Effects of the Antiepileptic Drug Valproic Acid in Glioblastoma. Cell. Physiol. Biochem. 2017, 44, 1591-1605. [CrossRef] [PubMed]

46. Cerami, E.; Gao, J.; Dogrusoz, U.; Gross, B.E.; Sumer, S.O.; Aksoy, B.A.; Jacobsen, A.; Byrne, C.J.; Heuer, M.L.; Larsson, E.; et al. The cBio cancer genomics portal: An open platform for exploring multidimensional cancer genomics data. Cancer Discov. 2012, 2, 401-404. [CrossRef] [PubMed]

47. Gao, J.; Aksoy, B.A.; Dogrusoz, U.; Dresdner, G.; Gross, B.; Sumer, S.O.; Sun, Y.; Jacobsen, A.; Sinha, R.; Larsson, E.; et al. Integrative analysis of complex cancer genomics and clinical profiles using the cBioPortal. Sci. Signal. 2013, 6, pl1. [CrossRef]

48. Wolf, M.; Gulich, R.; Lunkenheimer, P.; Loidl, A. Broadband dielectric spectroscopy on human blood. Biochim. Biophys. Acta 2011, 1810, 727-740. [CrossRef]

49. Huang, H.; Lin, H.; Zhang, X.; Li, J. Resveratrol reverses temozolomide resistance by downregulation of MGMT in T98G glioblastoma cells by the NF-kappaB-dependent pathway. Oncol. Rep. 2012, 27, 2050-2056. [CrossRef]

50. Qiu, Z.K.; Shen, D.; Chen, Y.S.; Yang, Q.Y.; Guo, C.C.; Feng, B.H.; Chen, Z.P. Enhanced MGMT expression contributes to temozolomide resistance in glioma stem-like cells. Chin. J. Cancer 2014, 33, 115-122. [CrossRef]

51. Silginer, M.; Weller, M.; Stupp, R.; Roth, P. Biological activity of tumor-treating fields in preclinical glioma models. Cell Death Dis. 2017, 8, e2753. [CrossRef]

52. Clark, P.A.; Gaal, J.T.; Strebe, J.K.; Pasch, C.A.; Deming, D.A.; Kuo, J.S.; Robins, H.I. The effects of tumor treating fields and temozolomide in MGMT expressing and non-expressing patient-derived glioblastoma cells. J. Clin. Neurosci. 2017, 36, 120-124. [CrossRef] [PubMed]

53. Overgaard, J. The current and potential role of hyperthermia in radiotherapy. Int. J. Radiat. Oncol. Biol. Phys. 1989, 16, 535-549. [CrossRef] 
54. Kessler, A.F.; Frombling, G.E.; Gross, F.; Hahn, M.; Dzokou, W.; Ernestus, R.I.; Lohr, M.; Hagemann, C. Effects of tumor treating fields (TTFields) on glioblastoma cells are augmented by mitotic checkpoint inhibition. Cell Death Discov. 2018, 4, 12. [CrossRef]

55. Navedo, M.F.; Amberg, G.C.; Votaw, V.S.; Santana, L.F. Constitutively active L-type Ca ${ }^{2+}$ channels. Proc. Natl. Acad. Sci. USA 2005, 102, 11112-11117. [CrossRef] [PubMed]

56. Park, S.Y.; Shim, J.H.; Kim, M.; Sun, Y.H.; Kwak, H.S.; Yan, X.; Choi, B.C.; Im, C.; Sim, S.S.; Jeong, J.H.; et al. MLCK and PKC Involvements via Gi and Rho A Protein in Contraction by the Electrical Field Stimulation in Feline Esophageal Smooth Muscle. Korean J. Physiol. Pharm. 2010, 14, 29-35. [CrossRef] [PubMed]

57. Klumpp, D.; Frank, S.C.; Klumpp, L.; Sezgin, E.C.; Eckert, M.; Edalat, L.; Bastmeyer, M.; Zips, D.; Ruth, P.; Huber, S.M. TRPM8 is required for survival and radioresistance of glioblastoma cells. Oncotarget 2017, 8, 95896-95913. [CrossRef]

58. Stegen, B.; Klumpp, L.; Misovic, M.; Edalat, L.; Eckert, M.; Klumpp, D.; Ruth, P.; Huber, S.M. K channel signaling in irradiated tumor cells. Eur. Biophys. J. 2016, 45, 585-598. [CrossRef]

59. Yao, K.; Nagashima, K.; Miki, H. Pharmacological, pharmacokinetic, and clinical properties of benidipine hydrochloride, a novel, long-acting calcium channel blocker. J. Pharmacol. Sci. 2006, 100, 243-261. [CrossRef]

60. Kobayashi, H.; Ohishi, T.; Nishiie, H.; Kobayashi, S.; Inoue, A.; Oka, T.; Nakamizo, N. Absorption, distribution and excretion after oral administration of 14C-benidipine hydrochloride in rats and dogs. Arzneim. Forsch. 1988, 38, 1742-1746.

61. Larkin, J.G.; Thompson, G.G.; Scobie, G.; Forrest, G.; Drennan, J.E.; Brodie, M.J. Dihydropyridine calcium antagonists in mice: Blood and brain pharmacokinetics and efficacy against pentylenetetrazol seizures. Epilepsia 1992, 33, 760-769. [CrossRef] [PubMed]

(C) 2019 by the authors. Licensee MDPI, Basel, Switzerland. This article is an open access article distributed under the terms and conditions of the Creative Commons Attribution (CC BY) license (http://creativecommons.org/licenses/by/4.0/). 